\title{
Data-based models for the prediction of dam behaviour: a review and some methodological considerations
}

\author{
F. Salazar ${ }^{1, *}$, M.Á. Toledo ${ }^{2}$, E. Oñate ${ }^{1}$, R. Morán ${ }^{2}$
}

\begin{abstract}
Keywords: Dam monitoring, Dam safety, Data analysis, Machine learning, Statistical models, Behaviour models
\end{abstract}

\section{Introduction}

Behaviour models are a fundamental component of dam safety systems, both for the daily operation and for long-term behaviour evaluation. They are built to calculate the dam response under safe conditions for a given load combination, which is compared to actual measurements of dam performance [1]. The result is an essential ingredient for dam safety assessment, together with visual inspection and engineering judgement [2].

Numerical models based on the finite element method (FEM) are widely used to predict dam response, in terms of displacements, strains and stresses. They are based on the physical laws governing the involved phenomena, what gives them some interesting features: a) they are useful for the design and, importantly, for dam safety assessment during the first filling, and b) they can be conveniently interpreted, provided that their parameters have physical meaning.

\footnotetext{
${ }^{*}$ Corresponding author

Email addresses: fsalazar@cimne.upc.edu (F. Salazar), matoledo@caminos.upm.es (M.Á. Toledo), onate@cimne.upc.edu (E. Oñate), rmoran@caminos.upm.es (R. Morán)

URL: www.cimne.com (F. Salazar)

${ }^{1}$ International Center for Numerical Methods in Engineering (CIMNE). Campus Norte UPC. Gran Capitán s/n. 08034. Barcelona, Spain

${ }^{2}$ Technical University of Madrid (UPM). Civil Engineering Department: Hydraulics and Energy. Profesor Aranguren s/n, 28040, Madrid, Spain
} 
On the contrary, some relevant indicators of dam safety, such as uplift pressure and leakage flow in concrete dams, cannot be predicted accurate enough with a numerical model [3], [4]. In addition, the knowledge on the stress-strain properties of the dam and foundation materials is always limited [5], and so is the prediction accuracy of FEM models [2].

These limitations, together with the availability of monitoring data, have fostered the application of statistical models to predict dam response. They have been used in dam safety analyses for decades as a complement to visual inspection and numerical models, to support decision making.

In recent years, there is a tendency towards automatising dam monitoring devices [2], what allows increasing the reading frequency and results in a greater amount of data available. On the one hand, it invites to extract as much information as possible in relation with dam safety condition [6]. On the other hand, it has revealed certain limitations of traditional statistical tools to manage dam monitoring data [7].
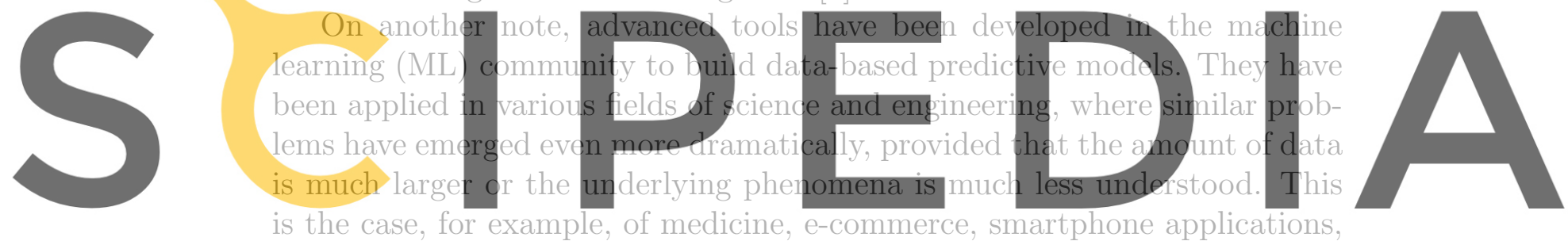

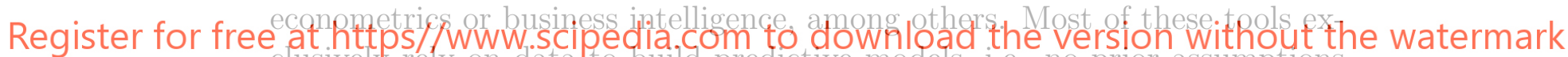
clusively rely on data to build predictive models, i.e. no prior assumptions

on the physics of the phenomenon have to be made beforehand [8].

The limitations of traditional statistical tools and the availability of these advanced learning algorithms have motivated dam engineers to search the possibilities of the latter for building dam behaviour models, as well as for analysing dam behaviour.

The paper reports a review on dam behaviour models based on monitoring data. The work focuses on prediction accuracy, although it also refers to model suitability for interpreting dam performance. The most popular techniques are dealt with in section 2, whereas some common issues in building data-based models and evaluating their results are analysed in section 3 . The analysis is performed on the basis of the review of 39 papers on the field. 


\section{Statistical and machine learning techniques used in dam moni- toring analysis}

The aim of these models is to predict the value of a given variable $Y \in \mathbb{R}$ (e.g. displacement, leakage flow, crack opening, etc.), in terms of a set of inputs $^{3} X \in \mathbb{R}^{d}$ :

$$
Y=\hat{Y}+\varepsilon=F(X)+\varepsilon
$$

$\varepsilon$ is an error term, which encompasses the measurement error, the model error, and the deviation of the dam response from the expected behaviour [1]. This term is important, given that it is frequently used to define safety margins and warning thresholds [2].

The models are fitted on the basis of a set of observed input data $x_{i}$, and the correspondent registered outputs $y_{i}$, where $i=1, \ldots, N$ and $N$ is the number of observations. Note that each $x_{i}$ is a vector of $d$ components, being $d$ the number of inputs.
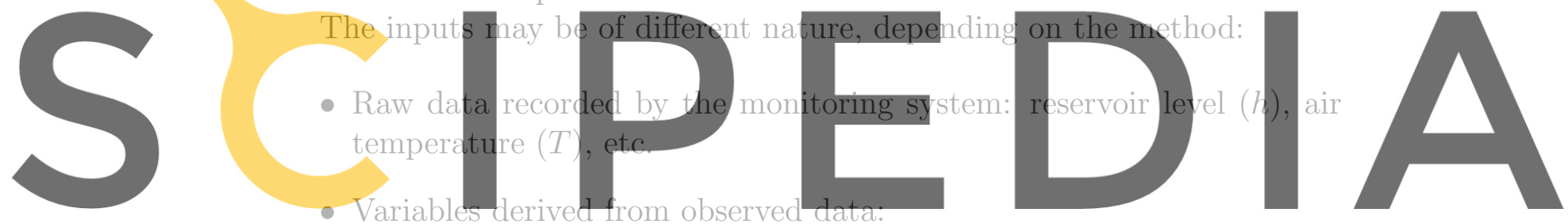

Register for free at https P/wwansieipedia.com to download the version without the watermark

- Moving averages

- Derivatives

\subsection{Hydrostatic-seasonal-time (HST) model}

The most popular data-based approach for dam monitoring analysis is the hydrostatic-seasonal-time (HST) model. It was first proposed by Willm and Beaujoint in 1967 [9] to predict displacements in concrete dams, and has

\footnotetext{
${ }^{3}$ Traditionally, the statistical models applied in dam monitoring analysis were based on causal variables, e.g., hydrostatic load and temperature, which are often termed "independent variables". On the contrary, other algorithms make use of transformed variables (such as gradients or moving averages), and non-causal observations (e.g. the previous value of the output). This has led to the use of various terms to refer to the model inputs, such as "predictors", "covariates", and "features". In this paper they are used indistinctly.
} 
been widely applied ever since. It is based on the assumption that the dam response is a linear combination of three effects:

$$
\hat{Y}=F_{1}(h)+F_{2}(s)+F_{3}(t)
$$

- A reversible effect of the hydrostatic load which is commonly considered in the form of a fourth-order polynomial of the reservoir level $(h)[1]$, $[10],[11]$ :

$$
F_{1}(h)=a_{0}+a_{1} h+a_{2} h^{2}+a_{3} h^{3}+a_{4} h^{4}
$$

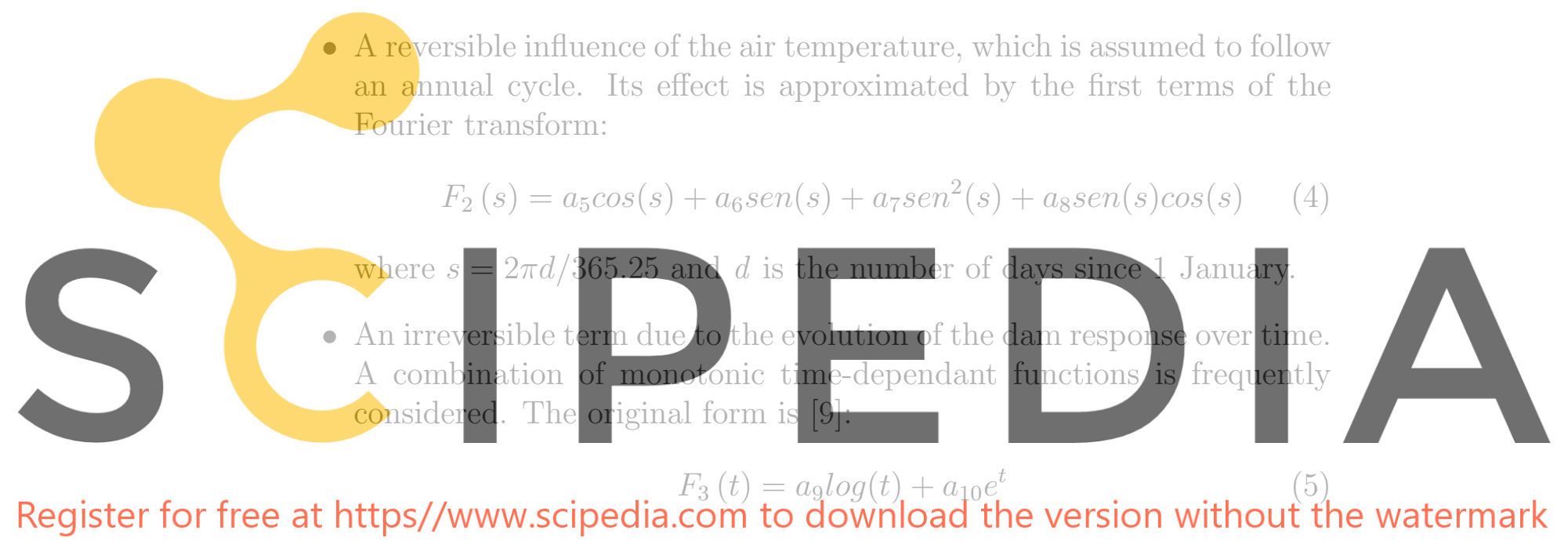

The model parameters $a_{1} \ldots a_{10}$ are adjusted by the least squares method: the final model is based on the values which minimise the sum of the squared deviations between the model predictions and the observations.

Some authors used variations of the original HST model, by using some heuristics or after a trial-and-error process. Mata [12] considered the irreversible effect by means of $F_{3}(t)=a_{9} t+a_{10} e^{-t}$. Chouinard and Roy [13] used a linear term in $t$ and a third-order polynomial of $h$. Simon et al. [11] chose $F_{3}(t)=a_{9} e^{-t}+a_{10} t+a_{11} t^{2}+a_{12} t^{3}+a_{13} t^{4}$, whereas Yu et al. [14] used $F_{3}(t)=a_{9} t+a_{10} t^{2}+a_{11} t^{3}$. Carrère applied a variation of HST in which the possibility of a sudden change in the dam response at a certain time is considered by adding a step function to the irreversible term [15].

The method makes use of strong assumptions on the response of the dam, which might not be accurate in general. In particular, the three effects are considered as independent, although it is well known that certain collinearity exists. The reservoir level affects the thermal response of the dam, provided 
that the air and water temperatures differ [16]. In some cases, the reservoir operation follows an annual cycle due to the evolution of the water demand, so there is a strong correlation between $h$ and $T$ [3], [17], [18], [19]. Collinearity may lead to poor prediction accuracy and, more importantly, to misinterpretation of the results [20].

Another limitation of the original form of HST model is that the actual air temperature is not considered. On one hand, this makes it more flexible, because it can be applied in dams where air temperature measurements are not available. On the other hand, it reduces its prediction accuracy for particularly warm or cold years [16], [17].

Several alternatives have been proposed to overcome this shortcoming. Penot et al. [21] introduced the HSTT method, in which the thermal periodic effect is corrected according to the actual air temperature. This procedure has been applied at Electricité de France (EDF) [16], [22] with higher accuracy than HST, especially during the 2003 European heat wave. Although the proposal of this nethod has been frequently attributed to Penot et al. Breitenstein ot al. [23] applied a simi ar scheme 20 years earlier. Other conmon choice is to replace the periodic component by the actual temperature in the dan hydrostatic-thermal-time (HTT) method. One diffi how to select the appropriate thermometers among those available. In arch

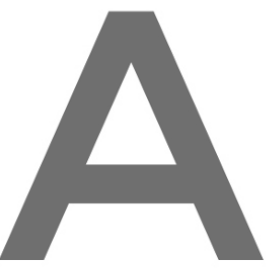

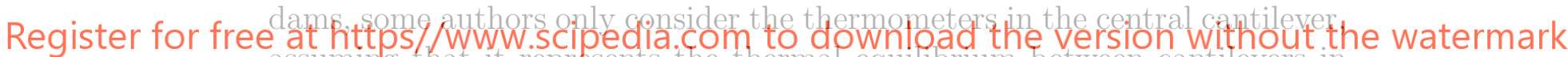
assuming that it represents the thermal equilibrium between cantilevers in the right and left margins [17]. Mata et al. [24] solved this issue by applying principal component analysis (PCA), while other authors [18] considered all the available instruments.

Although HST was originally devised for the prediction of displacements in concrete dams, it has also been applied to predict other variables. Simon et al. [11] estimated uplifts and leakage with HST, although they obtained more accurate results with neural networks (NN). Guedes and Coelho [25] built a model for the prediction of leakage in Itaipú Dam with the form $a_{1} h_{6,11}^{2}+a_{2} t+a_{3} t^{2}+a_{4} \log (1+t)$, where $h_{6,11}$ is the average reservoir level between 6 and 11 days before the measurement. Breitenstein et al. [23] also studied leakage, although they discarded both the seasonal and the temporal terms. Yu et al. [14] combined HST with PCA to predict the opening of a longitudinal crack in Chencun Dam.

A common feature to HST and its variations is that the output is computed as a linear combination of the inputs. Hence, they are all multi-lineal 
regression models (MLR), so their coefficients can be fitted by least squares. Other approaches based on MLR have been applied in dam safety, considering a larger set of inputs (e.g. [26], [27]).

\subsection{Models to account for delayed effects}

It is well known that dams respond to certain loads with some delay [4]. The most typical examples are:

- The change in pore pressure in an earth-fill dam due to reservoir level variation [28].

- The influence of the air temperature in the thermal field in a concrete dam body [11].

Other phenomena have been identified which are governed by similar processes. For example, Lombardi [3] noticed that the structural response of an arch dam to hydrostatic load comprised both an elastic and a viscous components. Hence, the displacements not only depended on the instantaneous reservoir level, but also on the past values. Sinnon et al. [11] reported that leakage flow at Bissorte Dam responded to rainfall and syoy melt with 4

Several approaches have been proposed to account for these effects. The

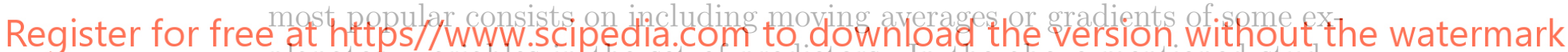
planatory variables in the set of predictors. In the above mentioned study,

Guedes and Coelho [25] predicted the leakage flow on the basis of the mean

reservoir level along a five-days period. Sánchez Caro [29] included the 30 and 60 days moving average of the reservoir level in the conventional HST formulation to predict the radial displacements of El Atazar Dam. Popovici et al. [30] used moving averages of 3,10 and 30 days of the air temperature, together with the pool level in the previous 3 days to the measurement to predict displacements in a buttress dam with neural networks (NN). Crépon and Lino [31] reported significant improvement in the prediction of piezometric levels and leakage flows by considering the accumulated rainfall and the derivative of the hydrostatic load as predictors.

This approach requires a criterion to determine which moving averages and gradients should be considered for each particular case. Demirkaya and Balcilar [27] performed a sensitivity analysis to select the number of past values to include both in an MLR and in a NN model. They used the same period for the external and internal temperatures, as well as for the 
reservoir level, and found that the most accurate results were obtained with an MLR model considering data from 30 previous days. Although their results compared well to those proposed by the participants in the 6th ICOLD Benchmark Workshop ${ }^{4}$ [32], they lacked physical meaning: they would imply that the dam responded with the same delay to the water level, the air temperature, and the internal temperature field.

Santillán et al. [33] proposed a methodology to select the optimal set of predictors among various gradients of air temperature and reservoir level.

They used the gradients instead of the moving averages to ensure independence among predictors (moving averages are correlated with the original correspondent variables). They combined it with NN to predict leakage flow in an arch dam.

A more formal alternative to conventional HST to account for delayed effects was proposed by Bonelli and Royet [34]. It is based on the hypothesis that the delayed effect depends on the convolution integral of the impulse
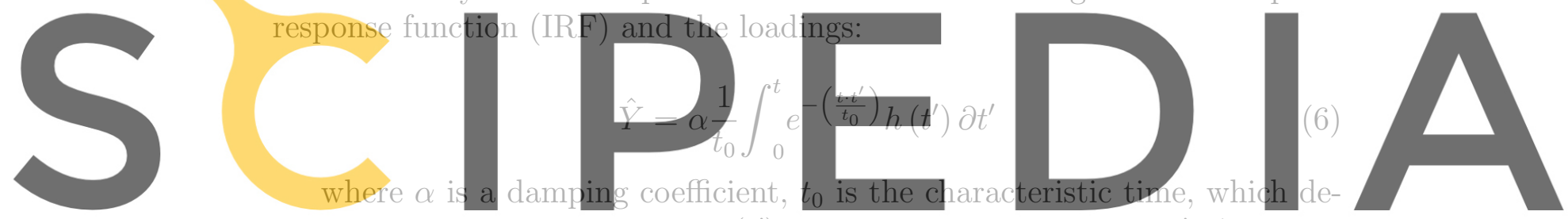

pends on the phenomenon, and $h\left(t^{\prime}\right)$ is the reservoir level at time $t^{\prime}$. Although

by means of numerical approximation. The advantage of this approach is

that the coefficients have physical meaning: the characteristic time provides insight into the lag with which the dam reacts to a variation in the input variable, whereas the damping reflects the relation between the amplitude of the reservoir level variation and that of the pore pressure in the location considered within the dam body.

A similar approach was followed by the same author in the frame of the above mentioned 6th ICOLD Benchmark Workshop [10]. In this case, it was intended to account for the delayed response of the dam in terms of the temperature field, with the final aim of predicting radial displacements.

\footnotetext{
${ }^{4}$ In the 6 th ICOLD Benchmark Workshop, the participants were asked to provide a data-based model for predicting the radial displacement of Schlegeiss arch dam for the period 1999-2000. Time histories of water level, air temperature and concrete temperatures at various locations were provided for the period 1992-2000, as well as the observed values of the target variable for the period 1992-1998.
} 
Lombardi et al. [3] suggested an equivalent formulation, also to compute the thermal response of the dam to changes in air temperature. Although the development was slightly different, the numerical approximation to the integral is totally equivalent. Lombardi arrived to the following expression [4]:

$$
\hat{Y}(t)=\alpha \cdot Y(t-\Delta t)+\left(1+\frac{\alpha}{\beta}-\frac{1}{\beta}\right) X(t)+\left(\frac{1}{\beta}-\frac{\alpha}{\beta}-\alpha\right) X(t-\Delta t)
$$

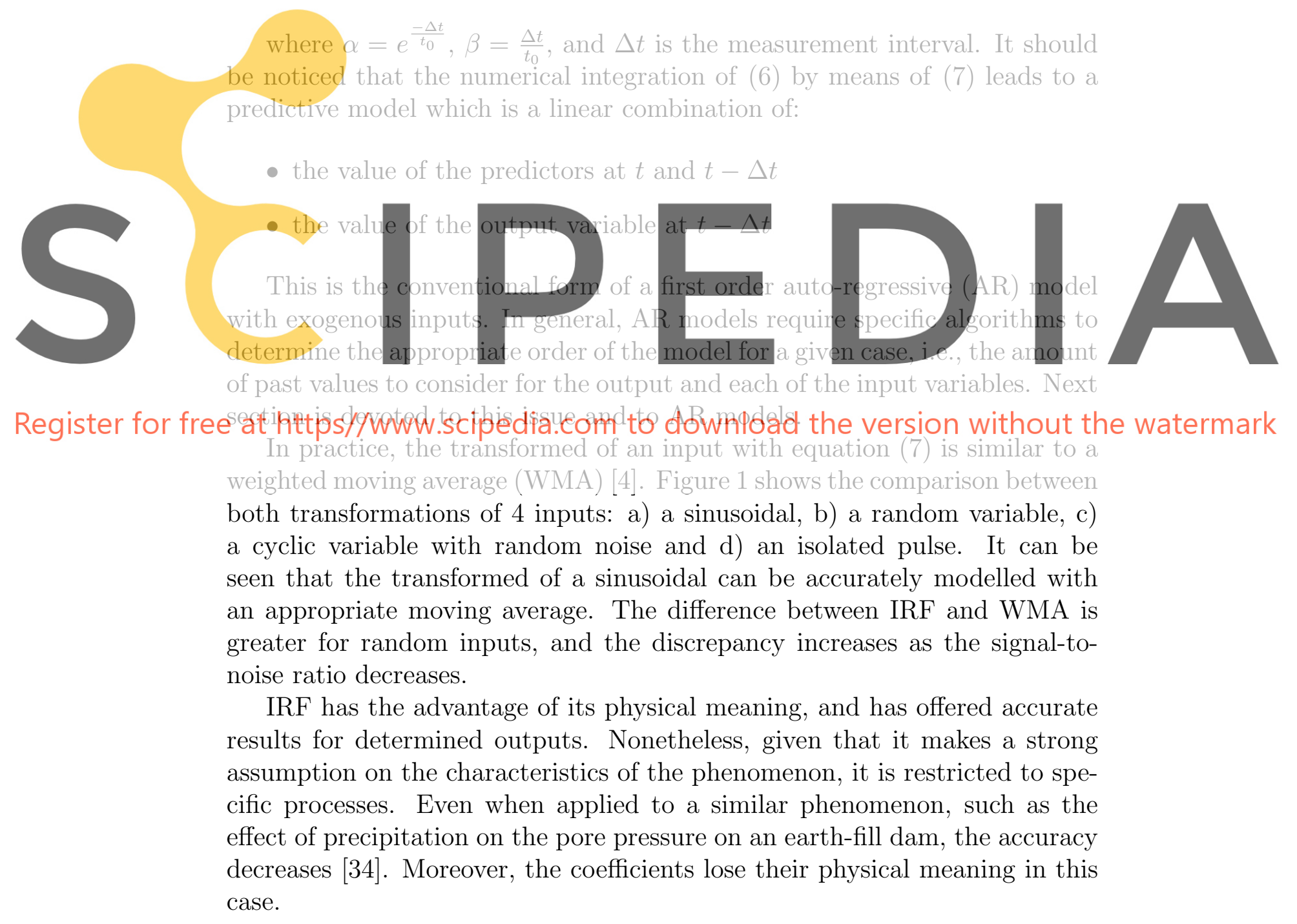


(a)

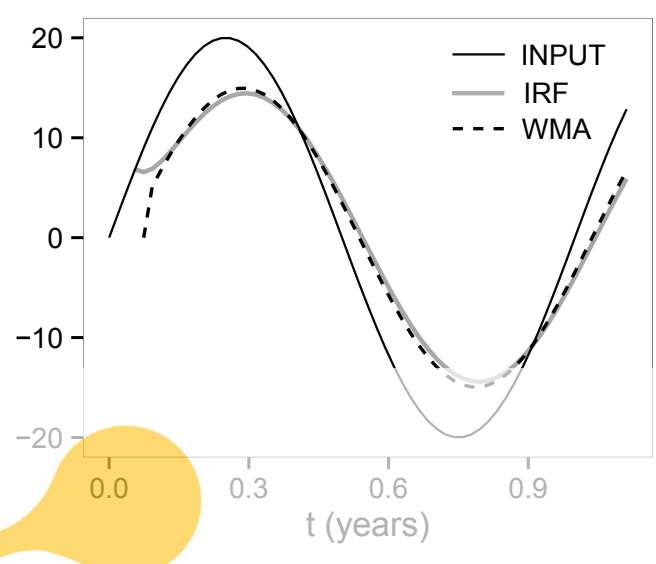

(b)

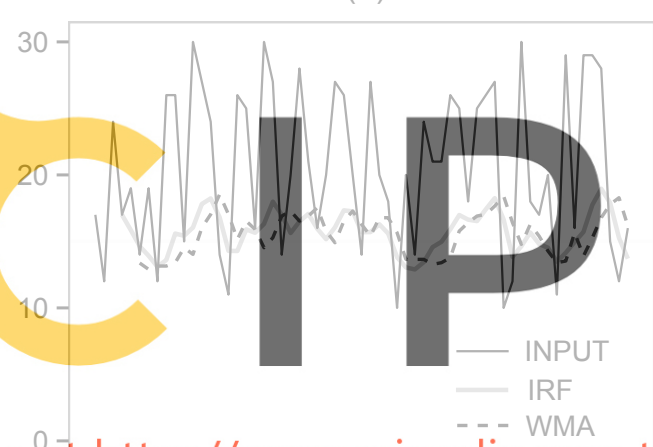

(c)

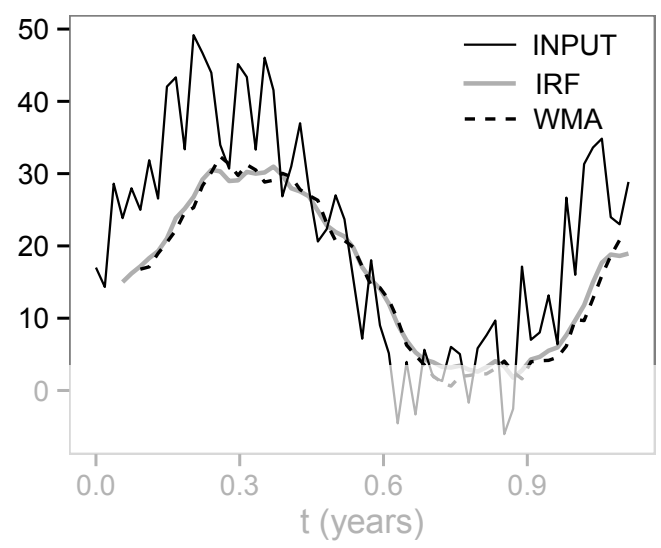

(d)

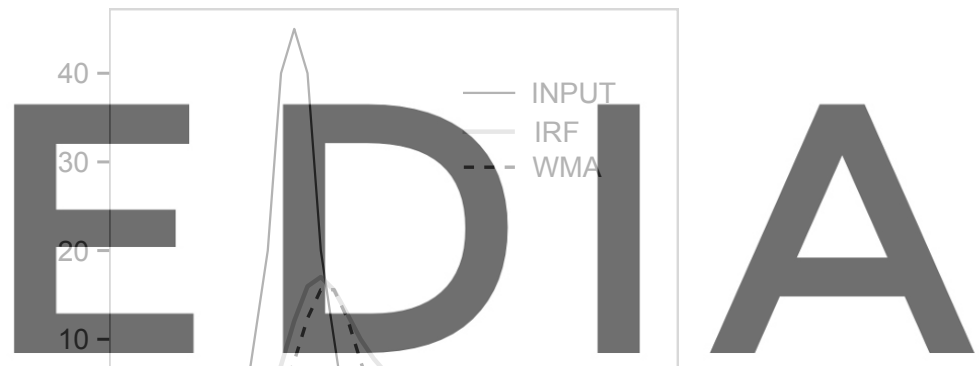

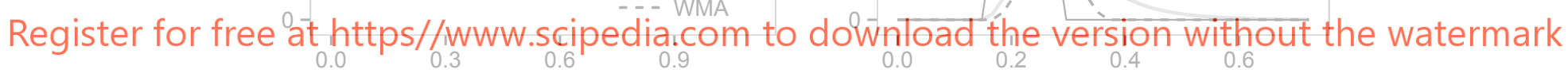
$\mathrm{t}$ (years)

$\mathrm{t}$ (years)

Figure 1: Comparison between impulse response function (IRF) and weighted moving average (WMA) for various inputs: a) sinusoidal, b) random, c) sinusoidal with random noise and d) impulse.

\subsection{Auto-regressive (AR) models}

The use of the previous (lagged) value of the output to calculate a prediction for current record may induce to question a) whether the observed previous value or the precedent prediction should be used, and b) whether the model parameters should be readjusted at every time step.

In general, using actual previous value and refitting the model should provide better prediction accuracy, but such model would not be able to detect anomalies: it would learn the abnormal behaviour and treat it as ordinary [3]. It depends on the data acquisition frequency and the kind of 
anomaly. Only sharp changes in dam response, occurring in a shorter lapse than the time between two consecutive records, could be captured. On the contrary, gradual changes would be incorporated to the model. Riquelme et al. [35] improved the accuracy of an NN model by several orders of magnitude by applying this approach.

The opposite alternative is to fit the model to data gathered for a given time period, and make long-term predictions on a step-by-step basis [36], i.e., predict the output at $t+1$, and use it (the prediction; not the observation)to estimate the value at $t+2$. This procedure may fail in error propagation [37], but in principle should be appropriate to unveil gradual anomalies.

An intermediate choice is to use the actual measurement of the output variable, without readjusting the model parameters. In this case, the coefficients obtained on the basis of a period of normal behaviour are applied to future observations, hence the model could detect changes in the relation between current and next values of the output.
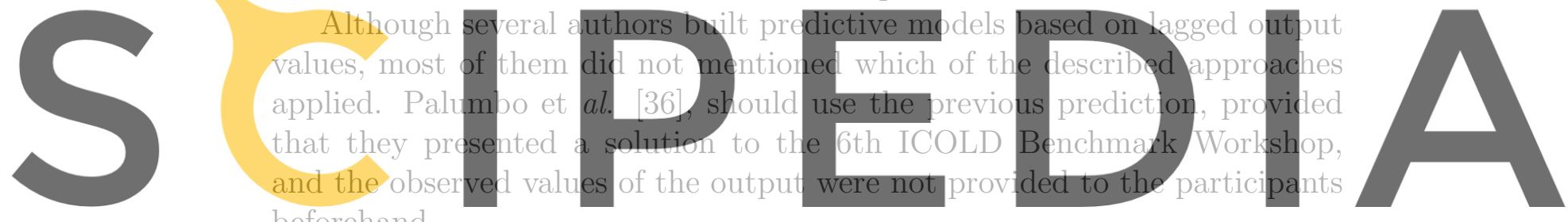

Register for free at htthe p/pssibility of ingluding past dalues of the variables is concidere the watermark

a criterion to select some of the available shall be defined. Otherwise, the

amount of predictors is quite high. For example, Piroddi and Spinelli [38]

considered the most general form of a non-linear autoregressive exogenous model (NARX), which depended on current and previous values of the input variables, on precedent values of the output, as well as on linear and nonlinear combinations of them. They applied a specific algorithm for selecting 11 predictors in the final model.

In general, these models prioritise prediction accuracy over explanatory capability. The greater the number of variables in the model, the harder it is to interpret and to isolate the effect of each component. Nonetheless, some procedures have been proposed to interpret models which parameters do not have physical meaning, as described in section 3.2.

\subsection{Neural networks (NN)}

Linear models are not well suited to reproduce non-linear behaviour, even though some actions are considered in the form of high order polynomials 
[13]. On the contrary, NN models are flexible, and allow modelling complex and highly non-linear phenomena. Although there are various types of NN models [39], the vast majority of applications for dam monitoring data analysis are based on the multilayer perceptron (MLP). Such models, as their name suggests, are comprised by a number of perceptrons (also called "units", or "neurons") organised in different layers: input, hidden, and output (Figure 2). In principle, several hidden layers can be used (see section 2.6), but one is mostly adopted in practice [39].

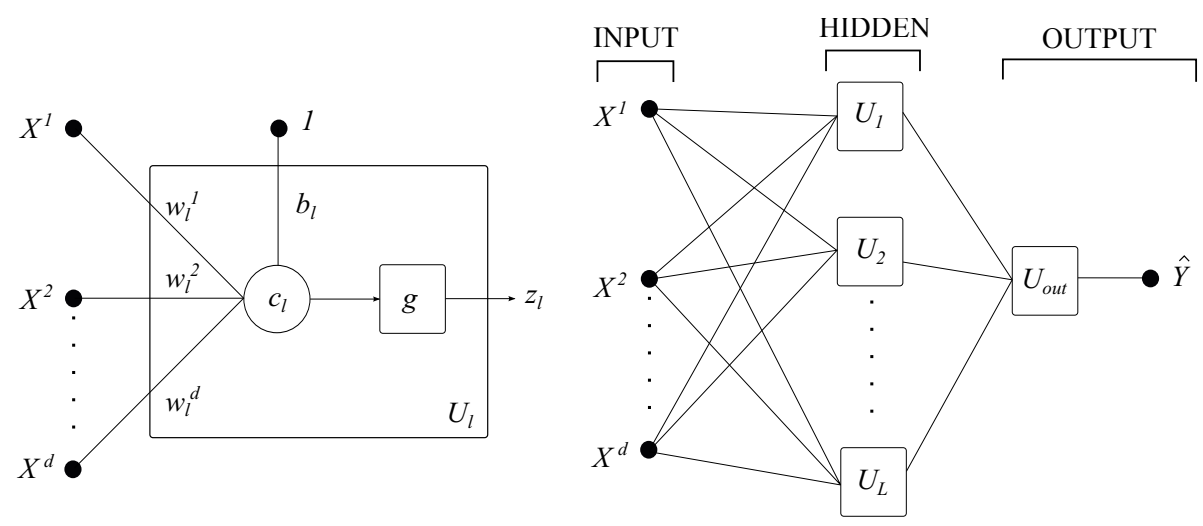

Figure 2: Left: schematic model of a perceptron $U_{l}$. Right: Multilayer Perceptron formed by $L$ units, $U_{1} \ldots U_{L}$

The input of each unit $U_{l}$ is a linear combination of the predictors $X^{j}$ :

$$
c_{l}=\sum_{j=1}^{d} X^{j} \cdot w_{l}^{j}+b_{l}
$$

which is later transformed by an activation function $g$ to compute the neuron's output:

$$
z_{l}=g\left(c_{l}\right)
$$

Several forms of $g$ can be chosen (non-linear in general), although sigmoid functions are often employed, such as the logistic (10) and the hyperbolic tangent (11) (Figure 3).

$$
g\left(c_{l}\right)=\frac{1}{1+e^{-c_{l}}}
$$




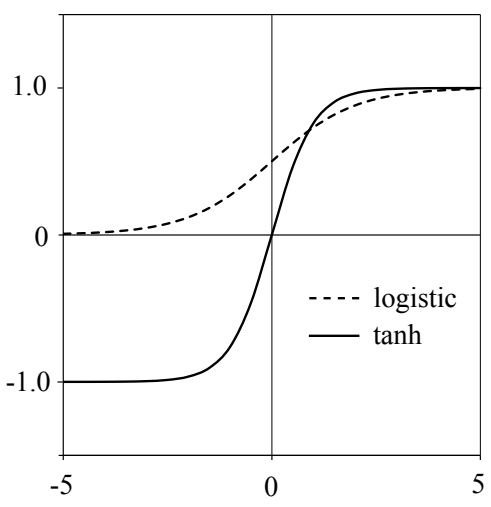

Figure 3: Common activation functions in NN models: logistic and hyperbolic tangent.

$$
g\left(c_{l}\right)=\frac{e^{c_{l}}-e^{-c_{l}}}{e^{c_{l}}+e^{-c_{l}}}
$$

The output layer may be composed of one of the described neurons, although a linear transform is frequently chosen, so that the overall model output is computed as:

$$
\hat{Y}=\sum_{l=1}^{L} w_{\text {out }}^{l} \cdot g\left(\sum_{j=1}^{d} X^{j} w_{l}^{j}+b_{l}\right)+b_{\text {out }}
$$

NN models can be thought of as an extension of MLR, which output $c_{l}$ is expanded by the perceptron through a non-linear transformation $g$ [8]. It should be noted (Figure 3) that the sigmoid functions have a linear interval, thus an unit with small weights performs a linear transform. On the contrary, it has horizontal asymptotes, which may cause numerical problems. While it is widely acknowledged that the variables shall be normalized before fitting an NN model, some authors restrict them to the range [0.1, 0.9] to avoid the above mentioned problems [40], [5], [41].

The most common learning algorithm is called bac-kpropagation: NN model parameters $\left\{w_{l}^{j}, b_{l}, w_{\text {out }}^{l}, b_{\text {out }}\right\}$ are randomly initialised, and iteratively updated to minimise a cost function (typically the sum of the squared errors), by means of the gradient descent method [8].

The issues to be considered for building an NN model are the following:

1. The best network architecture, i.e., number of layers and perceptrons in each layer, is not known beforehand. Some authors focus on the def- 
inition of an efficient algorithm for determining an appropriate network architecture [33], whereas others use conventional cross-validation [12] or a simple trial and error procedure [5].

2. The training process may reach a local minimum of the error function. The probability of occurrence of this event can be reduced by introducing a learning rate parameter [5].

3. The NN models are prone to over-fitting. Various alternatives are suitable to solve this issue, such as early stopping and regularisation [8].

The fitting procedures greatly differ among authors. While Simon et al. [11] trained an MLP with three perceptrons in one hidden layer for 200,000 iterations, Tayfur et al. [5] used regularization with 5 hidden neurons and 10,000 iterations. Neither of them followed any specific criterion to set the number of neurons. For his part, Mata [12] tested NN architectures with one hidden layer having 3 to 30 neurons on an independent test data set. He repeated the training of each NN model 5 times with different initialisation of the weights.

Kao and Loh [42] proposed a two-step procedure: first, the number of neurons was fixed whereas the optimal amount of iterations was computed. Second, NN models with different number of hidden nodes were trained with the selected amount of iterations, and the final architecture was chosen as the one which provided the lowest error in a validation set. However, their results showed no error increase with a greater number of units, which may be due to the small size of the validation set.

The results of the different studies are not comparable, due to the specific features of each case. Nonetheless, the lack of agreement on the training process suggests that similar results can be obtained with different criteria, provided enough care is taken to avoid over-fitting. This is in accordance with Hastie et al. [8], who stated that in general it is enough to set the architecture and compute the appropriate regularisation parameter, or vice versa.

NN models have been used regularly in dam monitoring in recent years. There is an increasing number of published studies, both in academic and professional journals. The most recent ICOLD bulletin on dam surveillance [2] mentions NN as an alternative to HST and deterministic models, although it terms the tool as a "possible future alternative" to be developed, what proves that it is far from being implemented in the daily practice. 


\subsection{Adaptive neuro-fuzzy systems (ANFIS)}

NN models do not require any previous knowledge on the dam behaviour. The consequences are twofold: on the one hand, unexpected interactions may be "discovered". On the other hand, engineering knowledge can hardly be exploited, apart from input selection and results interpretation.

Fuzzy logic allows inclusion of prior knowledge of the phenomenon, as opposed to the NN, which "learn" from the data. ANFIS models bring together the flexibility and ability to learn of the NNs with the feasibility of interpretation of fuzzy logic. In fact, ANFIS can be considered a class of NN [43]. They are meant for highly non-linear, complex phenomena which vary with time [44].

Among the different types of ANFIS schemes, most previous references in dam monitoring used Takagi-Sukeno (T-S) type, which singularity is that its output is a combination of linear functions [45]. As an exception, Opyrchal [46] used fuzzy logic to qualitatively locate seepage paths in Tresna and Dobczyce dams.

Fuzzy logic is based on the concept of membership function. Each continuous variable is decomposed into classes (for example, the reservoir level, which is continuous, can be transformed into "low", "medium" and "high"; see Figure 4). The particularity of fuzzy logic is that these classes have certain overlap. Thus, a given reservoir level will generally have a different degree of membership (between zero and one) for at least two classes. The number of classes must be prescribed by the modeller, whereas the shape and position of their membership functions are determined by the premise parameters $\nu, \lambda$ and $\mu$ (Eq. 17), to be determined during training.

The other essential component in an ANFIS model is a set of rules. Consider a simple example with two input variables $X^{j} ; j=1,2$ and two membership functions for each: $M F_{j k} ; k=1,2$. With this configuration, 4 rules $\left(R_{i}\right)$ can be defined:

$$
\begin{aligned}
& R_{1}: \text { if } X^{1} \in M F_{11} \wedge X^{2} \in M F_{21} \Rightarrow f_{1}=p_{1} X^{1}+u_{1} X^{2}+v_{1} \\
& R_{2}: \text { if } X^{1} \in M F_{11} \wedge X^{2} \in M F_{22} \Rightarrow f_{2}=p_{2} X^{1}+u_{2} X^{2}+v_{2} \\
& R_{3}: \text { if } X^{1} \in M F_{12} \wedge X^{2} \in M F_{21} \Rightarrow f_{3}=p_{3} X^{1}+u_{3} X^{2}+v_{3}
\end{aligned}
$$




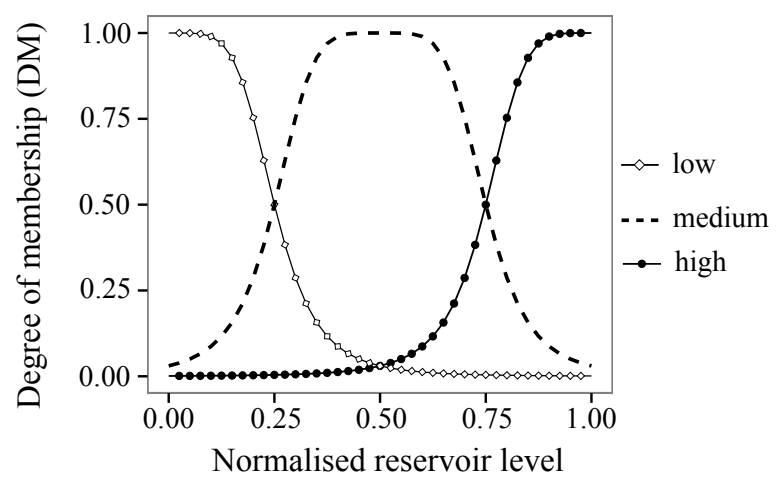

Figure 4: Possible transformation of the normalised reservoir level into three fuzzy sets with Gaussian form: "low", "medium" and "high".

$$
R_{4}: \text { if } X^{1} \in M F_{12} \wedge X^{2} \in M F_{22} \Rightarrow f_{2}=p_{4} X^{1}+u_{4} X^{2}+v_{4}
$$

where $p_{r}, u_{r}, v_{r}$ are the consequent parameters, to be adjusted during model training. It should be noticed that some of these rules can be omitted, i.e., $p_{r}=u_{r}=v_{r}=0$ for certain rules.

The model output is computed by means of 5 steps:

1. Compute the degree of membership of every input to each fuzzy category; for Gaussian membership functions:

$$
D M_{j k}=\frac{1}{1+\left[\left(\frac{X^{j}-\nu_{j k}}{\lambda_{j k}}\right)^{2}\right]^{\mu_{j k}}} ; j, k=1,2
$$

where $\nu_{j k}, \lambda_{j k}$ and $\mu_{j k}$ are the premise parameters.

2. Compute the product of the correspondent $D M_{j k}$, in accordance with the rules. In ANFIS terminology, these terms are referred to as the firing strengths $\left(w_{r} ; r=1 \ldots R\right)$ for each rule:

$$
\begin{aligned}
& w_{1}=D M_{11} \cdot D M_{21} \\
& w_{2}=D M_{11} \cdot D M_{22} \\
& w_{3}=D M_{12} \cdot D M_{21} \\
& w_{4}=D M_{12} \cdot D M_{22}
\end{aligned}
$$


3. Normalise the firing strengths:

$$
\overline{w_{r}}=\frac{w_{r}}{\sum w_{r}}
$$

4. Compute the output of each rule, as a linear function of the consequent parameters:

$$
O_{r}=\overline{w_{r}} f_{r}=\overline{w_{r}}\left(p_{r} X^{1}+u_{r} X^{2}+v_{r}\right), r=1 \ldots 4
$$

5. Combine the outputs of each rule to compute the overall output of the ANFIS model:

$$
\hat{Y}=\sum \overline{w_{r}} f_{r}, r=1 \ldots 4
$$

The final result is a combination of linear functions of the input variables. The non-linearity is modelled in the membership functions, which are typically Gaussian, as shown in the example of Figure 4. Each membership function is determined on the basis of 3 premise parameters. Therefore, the presented model has 24 parameters (12 for the membership functions, and 12 for the rules).

The parameters of these models are fitted with a hybrid method, in which the following steps are alternated:

1. The membership functions are fixed, and the consequent parameters are adjusted by least squares.

2. The premise parameters are modified by means of the gradient descent method.

The criterion of the user is more important for building ANFIS than for other kind of models. Both the prediction accuracy and the possibility of interpreting the results may vary greatly according to the number of inputs $(d)$, membership functions $(K)$ and rules $(R)$. It should be noted that the number of parameters in a first order T-S ANFIS model is $d \cdot K \cdot 3+R \cdot(d+1)$.

Rankovic et al. [47] prioritised prediction accuracy over model interpretation, by considering lagged values of both the input and output variables as predictors, resulting in an ANFIS model with $d=5, K=2$ and $R=32$. They used a zero-order T-S model, in which $p_{r}=u_{r}=0, \forall r \in R$, and twosided Gaussian membership functions, defined by 4 parameters each. No attempt was made to interpret the 32 rules.

On the contrary, $\mathrm{Xu}$ and $\mathrm{Li}$ [48] considered only 9 rules and could identify the worst environmental conditions for crack opening in Chencun Dam. 
For his part, Demirkaya [49] chose $d=5$ and $K=4$. Although he limited the number of rules to 4 , the final model had 84 parameters.

ANFIS models can be as flexible and accurate as NN, while allowing for introducing engineering knowledge to some extent. If the amount of rules and membership functions is low, the resultant model can be interpreted. Furthermore, an ANFIS model can be used for qualitatively describe dam behaviour, especially if the output is "fuzzyfied" into linguistic variables [48].

On the contrary, they may comprise a high number of parameters, even with a few rules, what results in high risk of over-fitting and low interpretability.

\subsection{Principal component analysis (PCA) and dimensionality reduction}

PCA is a well known technique in statistics. It was devised to transform a set of partially dependent variables into independent features called principal components (PCs), which are linear combination of the original variables. It is acknowledged that the first PCs contain the relevant information, whereas the less influential correspond to the signal noise. It has been used in dam monitoring for various purposes.

Mata et al. [24] used PCA to select the most useful thermometers to predict radial displacements in an arch dam. They pointed out the potentiality of this tool to select a group of sensors to be automatised in a given dam.

Yu et al. [14] applied PCA to a group of sensors to measure the opening of a longitudinal crack in an arch dam. They reported that PCA was useful for reducing the dimensionality of the problem, as well as to separate the signal from the noise. They also defined alarm thresholds as a function of the first PCs. Cheng and Zheng [50] also applied PCA to the outputs, to separate the effect of the causal variables from the signal noise.

Similar applications were due to Chouinard et al. [19], and Chouinard and Roy [13], who extracted PCs from a set of outputs (radial displacements at pendulums) to better understand the behaviour of the structure. They focused in the model interpretation, rather than in the prediction accuracy. In this line, Nedushan [51] extracted PCs from a group of sensors to analyse them jointly, as well as to identify the cause-effect relations by means of stepwise linear regression. He defined a set of predictors (reservoir level, temperature and time), and built linear regression models by adding the most relevant one by one.

A limitation of PCA is that only linear relations between variables are considered. If the dependency is non-linear, it may lead to misinterpretation 
of the results. Non-linear principal component analysis (NPCA) can be an alternative, as showed by Loh et al. [52] and Kao and Loh [42], who applied it by means of auto-associative neural networks (AANN) to predict radial displacements in an arch dam.

AANN are a special kind of NN models, formed by 5 layers (Figure 5), which can be viewed as two NN models put in series. The intermediate (bottleneck) layer has fewer neurons than the number of model inputs, and the target outputs equal the inputs. Thus, the first part of the model reduces its dimensionality, computing some sort of non-linear PCA. The right-handside of the AANN is a conventional NN which inputs are the non-linear PCs.

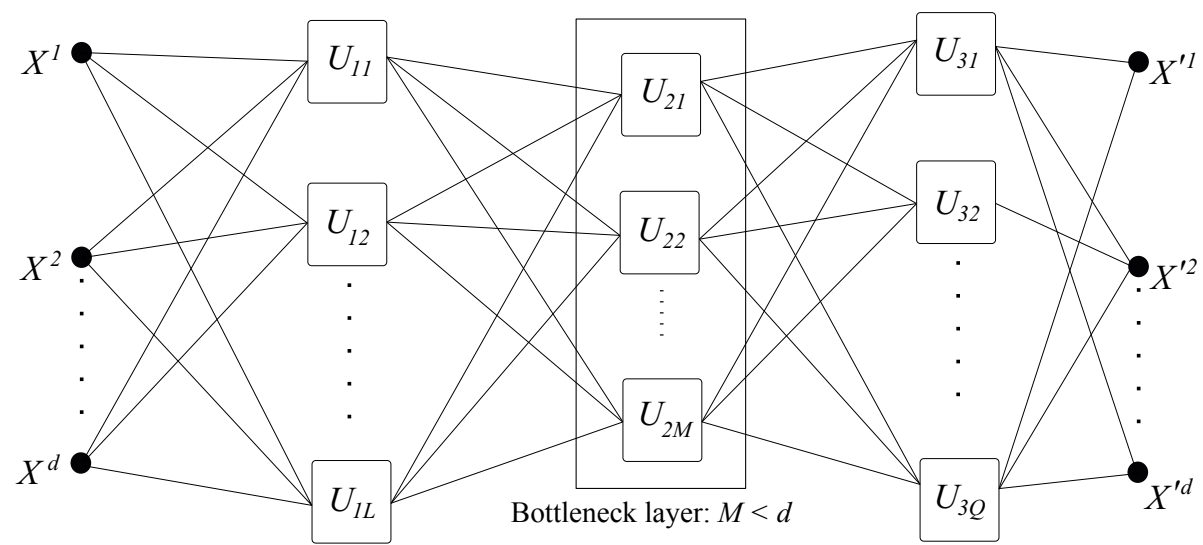

Figure 5: Architecture of an auto-associative neural network. There are 3 hidden layers between the inputs and the output. The central one is called "bottleneck" layer, and shall have fewer nodes than model inputs, so that each one can be considered a non-linear principal component of the inputs.

Jung et al. [53] developed a methodology to identify anomalies in piezometric readings in an earth-fill dam by means of moving PCA (MPCA), which is conventional PCA applied to different time periods. The goal was to detect significant variations in the PCs over time, which would reveal a change in dam behaviour.

PCA is mostly applied to input and/or output variable selection. The first option may increase the prediction accuracy, whereas the second can be useful for managing very large dams with a large amount of devices. For example, more than 8,000 instruments were installed to control the behaviour of the Three Gorges Dam [14]. 


\subsection{Other ML techniques}

There is a wide variety of ML algorithms which can be useful for dam monitoring data analysis. Their accuracy depends on the specific features of every prediction task. Given that research on ML is a highly active field, the algorithms are constantly improved and new practical applications are reported each year. Some of them have been applied to dam monitoring analysis. They are considered in this section more briefly than others, because they have been scarcely applied in dam engineering so far. This does not mean that they can not offer advantages over the methods described previously.

Support Vector Machines (SVM) stand among the most popular ML algorithms nowadays. They combine a non-linear transformation of the predictor variables to a higher dimensional space, a linear regression on the transformed variables, and an $\varepsilon$-insensitive error function that neglects errors below a given threshold [54]. Cheng and Zheng [50] used SVM in combination with PCA for short-term prediction of the response of Minhuatan gravity dam. Although the results were highly accurate, the computational time was high. Rankovic et al. [55] built a behaviour model based on SVM for predicting tangential displacements.

K-nearest neighbours (KNN) is a non-parametric method which requires no assumptions about the physics of the problem; it is solely based on the observed data. The KNN method basically consists on estimating the value of the target variable as the weighted average of observed outputs in similar conditions within the training set. The similarity between observed values is measured as the Euclidean distance in the $d$-dimensional space defined by the input variables.

A clear disadvantage of this type of model is that if the Euclidean distance is used as measure of similarity, all the predictors are given the same relevance. Hence, including a low relevant variable may result in a model with poor generalisation capability. As a consequence, variable selection is a critical aspect for fitting a KNN model.

Saouma et al. [56] presented a solution to the 6th ICOLD Benchmark Workshop based on KNN. To determine the similarity of observations, they used only two significant predictors (the reservoir level and a thermometer in the dam body) among the eight available. This selection of variables was performed by trial and error, although other criteria exist, as described in the next section. 
Stojanovic et al. [26] combined greedy MLR with variable selection by means of genetic algorithms (GA). Unlike HST, they considered all the observed variables in various forms (e.g. $h, h^{2}, h^{3}, \sqrt{h}$, etc.). They defined a methodology to select the best set of predictors which could be useful to update the predictive model in case of missing variables. A similar approach was followed by $\mathrm{Xu}$ et al. [57], though with a smaller set of potential inputs.

The authors [58] performed a comparative study among various statistical and ML methods, including HST, NN, and others which had been never used before in dam monitoring, such as random forests $(\mathrm{RF})$ or boosted regression trees (BRT). It was reported that innovative ML algorithms offered the most accurate results, although no one performed better for all 14 outputs analysed, which corresponded to radial and tangential displacements and leakage flow in an arch dam.

\section{Methodological considerations for building behaviour models}

While each model has specific issues to take into account, there are also common aspects to consider when developing a prediction model, regardless of the technique. They are discussed in this section, in comparison with a selection of papers presented at conferences and scientific journals in recent years. It is not an exhaustive review: the studies were selected on the basis of their relevance and interest, following the authors' criterion.

The Tables ?? and ?? summarise the main characteristics of the studies reviewed. It was found that most of them (28/39) considered radial displacements, especially in arch dams (22/39). This reflects the greater concern of dam engineers for this variable and dam typology, although other indicators such as leakage or uplift are acknowledged as equally relevant for dam safety [4]. The lower frequency with which the latter are chosen as target variables may be partly due to their more complex behaviour, what makes them harder to reproduce and interpret [4]. The HST and MLR methods, which have been the only available for a long time, are often incapable to model them accurately [11], although some references exist [25], [23].

Table 1: Review summary (1)

\begin{tabular}{|c|c|c|c|c|c|c|c|c|}
\hline Id & Author & Year & Dam & & Country & Typology & Output & \# Outputs \\
\hline 1 & Breitenstein [23] & 1985 & Limberg, & Mooser, & Switzerland & ARC, GRA, & RAD & 7 \\
\hline 2 & Breitenstein [23] & 1985 & $\begin{array}{l}\text { Drossen } \\
\text { Limberg, } \\
\text { Drossen }\end{array}$ & Mooser, & Switzerland & $\begin{array}{l}\text { ARC } \\
\text { ARC, GRA, } \\
\text { ARC }\end{array}$ & LEAK & 6 \\
\hline
\end{tabular}

Continued on next page 
Table 1 - continued from previous page

\begin{tabular}{|c|c|c|c|c|c|c|c|}
\hline Id & Author & Year & Dam & Country & Typology & Output & \# Outputs \\
\hline 3 & Guedes [25] & 1985 & São Simão & Brazil & $\mathrm{EF}+\mathrm{GRA}$ & RAD & 1 \\
\hline 4 & Guedes [25] & 1985 & Água Vermelha & Brazil & $\mathrm{EF}+\mathrm{GRA}$ & RAD & 1 \\
\hline 5 & Guedes [25] & 1985 & Funil & Brazil & $\mathrm{ARC}$ & PIEZ & 1 \\
\hline 6 & Guedes [25] & 1985 & Sobradinho & Brazil & $\mathrm{EF}+\mathrm{GRA}$ & JOINT & 1 \\
\hline 7 & Guedes [25] & 1985 & Itaipú & Brazil & GRA & LEAK & 1 \\
\hline 8 & Bonelli [34] & 2001 & $\begin{array}{l}\text { Alzitone, Cham- } \\
\text { boux, La Verne }\end{array}$ & France & $\mathrm{EF}$ & PIEZ & $9,6,4$ \\
\hline 9 & Bonelli [10] & 2001 & Schelegeis & Austria & ARC & RAD & 1 \\
\hline 10 & Carrere [15] & 2001 & Schelegeis & Austria & ARC & RAD & 1 \\
\hline 11 & Saouma $[56]$ & 2001 & Schelegeis & Austria & ARC & RAD & 1 \\
\hline 12 & Palumbo [36] & 2001 & Shclegeis & Austria & ARC & RAD & 1 \\
\hline 13 & Nedushan [51] & 2002 & Chute-à-Caron & Canada & GRA & RAD, TAN, & $1,1,1$ \\
\hline 14 & Piroddi [38] & 2003 & Schelegeis & Austria & ARC & RAD & 1 \\
\hline 15 & Tayfur [5] & 2005 & Jeziorsko & Poland & CFRD & PIEZ & 4 \\
\hline 16 & De Sortis [59] & 2006 & Ancipa & Italy & BUT & RAD & 5 \\
\hline 17 & De Sortis [59] & 2006 & Sabbione & Italy & BUT & RAD & 3 \\
\hline 18 & De Sortis [59] & 2006 & Malga Bissina & Italy & BUT & RAD & 5 \\
\hline 19 & S. Caro [29] & 2007 & El Atazar & Spain & ARC & RAD & 46 \\
\hline 20 & Léger [18] & 2007 & Schelegeis & Austria & $\mathrm{ARC}$ & RAD & 1 \\
\hline 21 & $\mathrm{Su}[60]$ & 2007 & $?$ & China & AG & VERT & 1 \\
\hline 22 & Panizzo [61] & 2007 & Pieve di Cadore & Italy & AG & RAD & 1 \\
\hline 23 & Lombardi [4] & 2008 & $?$ & $?$ & $\mathrm{ARC}$ & RAD & 1 \\
\hline 24 & Lombardi [4] & 2008 & $?$ & $?$ & $\mathrm{ARC}$ & LEAK & 1 \\
\hline 25 & Bonelli [62] & 2007 & $?$ & $?$ & $\mathrm{EF}$ & PIEZ & 14 \\
\hline 26 & Bonelli [28] & 2008 & $?$ & $?$ & $\mathrm{EF}$ & PIEZ & 16 \\
\hline 27 & $\mathrm{Yu}[14]$ & 2010 & Chencun & China & AG & CRACK & 5 \\
\hline 28 & Perner [63] & 2010 & Zillergruendl & Austria & $\mathrm{ARC}$ & RAD & 2 \\
\hline 29 & Demirkaya [49] & 2010 & Schelegeis & Austria & ARC & RAD & 1 \\
\hline 30 & Riquelme [35] & 2011 & La Baells & Spain & ARC & RAD & 1 \\
\hline 32 & Mata [12] & 2011 & Alto Rabagão & Portugal & ARC & RAD & 1 \\
\hline 31 & Rankoviĉ [47] & 2012 & Bocac & $\begin{array}{l}\text { Bosnia } \\
\text { Herzegovina }\end{array}$ & ARC & RAD & 2 \\
\hline 33 & $\mathrm{Xu}[57]$ & 2012 & Chencun & China & $\mathrm{AG}$ & CRACK & 1 \\
\hline 34 & Demirkaya [27] & 2012 & Schelegeis & Austria & $\mathrm{ARC}$ & RAD & 1 \\
\hline 35 & Demirkaya [27] & 2012 & Schelegeis & Austria & ARC & RAD & 1 \\
\hline 36 & Cheng [50] & 2013 & Mianhuatan & China & GRA & RAD & 12 \\
\hline 37 & Cheng [50] & 2013 & Mianhuatan & China & GRA & UP & 16 \\
\hline 38 & Popovici [30] & 2013 & Gura Râului & Romania & BUT & $\begin{array}{l}\text { RAD, TAN, } \\
\text { ROCK }\end{array}$ & $2,2,3$ \\
\hline 39 & Tatin [16] & 2013 & Castelnau & France & GRA & RAD & 1 \\
\hline 40 & Tatin $[16]$ & 2013 & Castelnau & France & GRA & RAD & 1 \\
\hline 41 & $\mathrm{Li}[64]$ & 2013 & Wanfu & China & $\mathrm{ARC}$ & RAD & 4 \\
\hline
\end{tabular}

Continued on next page 
Table 1 - continued from previous page

\begin{tabular}{|c|c|c|c|c|c|c|c|}
\hline Id & Author & Year & Dam & Country & Typology & Output & \# Outputs \\
\hline 42 & $\mathrm{Li}[64]$ & 2013 & Wanfu & China & ARC & RAD & 4 \\
\hline 43 & Simon [11] & 2013 & Pareloup & France & ARC & PIEZ & 1 \\
\hline 44 & Simon [11] & 2013 & Bissorte & France & GRA & LEAK & 4 \\
\hline 45 & Simon [11] & 2013 & Monteynard & France & $\mathrm{ARC}$ & RAD & 1 \\
\hline 46 & Simon [11] & 2013 & Monteynard & France & $\mathrm{ARC}$ & RAD & 1 \\
\hline 47 & Nourani [65] & 2013 & Sahand & Iran & $\mathrm{EF}$ & PIEZ & 4 \\
\hline 48 & Kao [42] & 2013 & Fei-Tsui & Taiwan & $\mathrm{ARC}$ & RAD & 13 \\
\hline 49 & Kao [42] & 2013 & Fei-Tsui & Taiwan & $\mathrm{ARC}$ & RAD & 13 \\
\hline 50 & Kao [42] & 2013 & Fei-Tsui & Taiwan & $\mathrm{ARC}$ & RAD & 13 \\
\hline 51 & Mata [24] & 2013 & Alto Lindoso & Portugal & $\mathrm{ARC}$ & RAD & 5 \\
\hline 52 & Jung [53] & 2013 & $?$ & USA & $\mathrm{EF}$ & PIEZ & 1 \\
\hline 53 & Stojanovic $[26]$ & 2013 & Bocac & $\begin{array}{l}\text { Bosnia } \\
\text { Herzegovina }\end{array}$ & ARC & $\mathrm{RAD}$ & 1 \\
\hline 54 & Rankoviĉ [41] & 2014 & Iron Gate 2 & Serbia/ Ro- & $\mathrm{EF}+\mathrm{GRA}$ & PIEZ & 2 \\
\hline 55 & Rankoviĉ [41] & 2014 & Iron Gate 2 & $\underset{\text { Serbia/ Ro- }}{\operatorname{mania}}$ & $\mathrm{EF}+\mathrm{GRA}$ & PIEZ & 2 \\
\hline 56 & Santillán [33] & 2014 & La Baells & $\begin{array}{l}\text { mania } \\
\text { Spain }\end{array}$ & $\mathrm{ARC}$ & LEAK & 1 \\
\hline 57 & Salazar $[58]$ & 2014 & La Baells & Spain & $\mathrm{ARC}$ & RAD, TAN, & $5,5,4$ \\
\hline 58 & Rankoviĉ [55] & 2014 & Iron Gate 2 & $\begin{array}{l}\text { Serbia/ Ro- } \\
\text { mania }\end{array}$ & $\mathrm{EF}+\mathrm{GRA}$ & $\begin{array}{l}\text { LEAK } \\
\text { TAN }\end{array}$ & 2 \\
\hline
\end{tabular}

Table legend

Table 2: Review summary (2)

\begin{tabular}{|c|c|c|c|c|c|c|}
\hline Id & Model & Inputs & Training set & Validation set & \% Test & Error metric \\
\hline 1 & MLR & H,S,t,Tair, d(Tair), d(H) & $10 / 14600$ & $0.0 /$ & $0 \%$ & $R^{2}$ \\
\hline 2 & MLR & $\mathrm{H}$ & $10 / 14600$ & $0.0 /$ & $0 \%$ & $R^{2}$ \\
\hline 3 & MLR & H, mav(Tair) & $1 / 103$ & $0.0 /$ & $0 \%$ & $r$ \\
\hline 4 & MLR & H, mav(Tair) & $0.5 / 63$ & $0.0 /$ & $0 \%$ & $r$ \\
\hline 5 & MLR & $t, \operatorname{mav}(\mathrm{H})$ & $2 / 230$ & $0.0 /$ & $0 \%$ & $r$ \\
\hline 6 & MLR & $\mathrm{t}, \operatorname{mav}(\mathrm{Tc})$ & $2.5 / 66$ & $0.0 /$ & $0 \%$ & $r$ \\
\hline 7 & MLR & $\mathrm{t}, \operatorname{mav}(\mathrm{H})$ & $0.5 / 86$ & $0.0 /$ & $0 \%$ & $r$ \\
\hline 8 & IRF & $\mathrm{H}, \operatorname{lag}(\mathrm{H}), \mathrm{P}, \operatorname{lag}(\mathrm{P}), \mathrm{t}$ & Var/Var & $0.0 /$ & $0 \%$ & - \\
\hline 9 & IRF & H, Tair & $7 / 2557$ & $2.0 / 730$ & $22 \%$ & - \\
\hline 10 & HST & H, Tair & $7 / 2557$ & $2.0 / 730$ & $22 \%$ & $r, R^{2}, \sigma_{\epsilon}$ \\
\hline 11 & KNN & $\mathrm{H}, \mathrm{Tc}$ & $7 / 2557$ & $2.0 / 730$ & $22 \%$ & $r, R^{2}, \sigma_{\epsilon}$ \\
\hline 12 & NARX & $\begin{array}{l}\text { H, Tair, Tc, } \operatorname{lag}(\mathrm{H}), \\
\operatorname{lag}(\mathrm{Tc}), \operatorname{lag}(\text { Tair) }\end{array}$ & $7 / 2555$ & $2.0 / 730$ & $22 \%$ & $R M S E$ \\
\hline 13 & $\mathrm{NN}$ & $\mathrm{Tc}, \mathrm{t}$ & $1.5 / 548$ & $1.5 / 548$ & $50 \%$ & $R^{2}$ \\
\hline 14 & NARX & $\begin{array}{l}\text { H, Tair, Tc, } \operatorname{lag}(\mathrm{H}), \\
\operatorname{lag}(\mathrm{Tc}), \operatorname{lag}(\text { Tair })\end{array}$ & $7 / 2555$ & $2.0 / 730$ & $22 \%$ & $M S E$ \\
\hline
\end{tabular}




\begin{tabular}{|c|c|c|c|c|c|c|}
\hline \multicolumn{7}{|c|}{ Table 2 - continued from previous page } \\
\hline Id & Model & Inputs & Training set & Validation set & \%Test & Error metric \\
\hline 15 & NN & $\mathrm{H}$ & $1 / 26$ & $2.0 / 52$ & $67 \%$ & $\begin{array}{l}R M S E, \quad M A E, \\
R^{2}\end{array}$ \\
\hline 16 & HST & $\mathrm{H}, \mathrm{S}, \mathrm{t}$ & $\begin{array}{l}2 \text { to } 15 / 730 \text { to } \\
5475\end{array}$ & $0.0 /$ & $0 \%$ & $r, \sigma_{\epsilon}, \frac{\sigma_{\epsilon}}{D / 2}$ \\
\hline 17 & HST & $\mathrm{H}, \mathrm{S}, \mathrm{t}$ & $5 / 1825$ & $0.0 /$ & $0 \%$ & $r, \sigma_{\epsilon}, \frac{\sigma_{\epsilon}}{D / 2}$ \\
\hline 18 & HST & $\mathrm{H}, \mathrm{S}, \mathrm{t}$ & $9 / 3285$ & $0.0 /$ & $0 \%$ & $r, \sigma_{\epsilon}, \frac{\sigma_{\epsilon}}{D / 2}$ \\
\hline 19 & MLR & $\begin{array}{l}\mathrm{H}, \quad \operatorname{mav}(\mathrm{H}), \quad \mathrm{S}, \quad \text { Tair, } \\
\operatorname{mav}(\text { Tair })\end{array}$ & $24.5 / 8943$ & $0.0 /$ & $0 \%$ & $\sigma_{\epsilon}, M S E$ \\
\hline 20 & HTT & $\mathrm{H}, \mathrm{Tc}, \mathrm{t}$ & $5 / 1825$ & $0.0 /$ & $0 \%$ & $r$ \\
\hline 21 & WNN & $\mathrm{H}, \mathrm{S}, \mathrm{t}$ & $11 / 44$ & $2.0 / 8$ & $15 \%$ & $M A E$ \\
\hline 22 & $\mathrm{NN}$ & H, lag(rad), Tair, Tc & $7 / 2555$ & $0.0 /$ & $0 \%$ & $R^{2}, \quad p d f(\varepsilon)$, \\
\hline 23 & IRF & $\mathrm{H}, \operatorname{lag}(\mathrm{H}), \operatorname{lag}(\mathrm{rad})$, Tair & $4 / ?$ & $0.0 /$ & $0 \%$ & $\sigma_{\epsilon}$ \\
\hline 24 & IRF & H, lag(H), lag(seep) & $5 / ?$ & $0.0 /$ & $0 \%$ & - \\
\hline 25 & IRF & $\mathrm{H}, \operatorname{lag}(\mathrm{P})$ & $3 / 167$ & $0.0 /$ & $0 \%$ & $R^{2}$ \\
\hline 26 & IRF & $\mathrm{H}, \mathrm{Hd}, \operatorname{lag}(\mathrm{P})$ & var/var & $0.0 /$ & $0 \%$ & $R^{2}$ \\
\hline 27 & HST & $\mathrm{H}, \mathrm{S}, \mathrm{t}$ & $10 / 1200$ & $0.0 /$ & $0 \%$ & $r$ \\
\hline 28 & HYB & $\mathrm{H}, \mathrm{Tc}, \mathrm{t}$ & $22 / 8030$ & $0.0 /$ & $0 \%$ & - \\
\hline 29 & ANFIS & H, Tair, Tc & $6 / 2044$ & $1.0 / 365$ & $15 \%$ & $R M S E$ \\
\hline 30 & $\mathrm{NN}$ & $\mathrm{H}, \mathrm{T}, \operatorname{mav}(\mathrm{T}), \operatorname{lag}(\mathrm{rad})$ & $18 / 706$ & $12.0 / 470$ & $40 \%$ & $M A P E$ \\
\hline 32 & $\mathrm{NN}$ & $\mathrm{H}, \mathrm{S}$ & $23 / 914$ & $1.8 / 69$ & $7 \%$ & $\begin{array}{l}\text { MAE, } \\
\text { MaxAE, r }\end{array}$ \\
\hline 31 & ANFIS & $\operatorname{lag}(\mathrm{H}), \operatorname{lag}(\mathrm{S}), \operatorname{lag}(\mathrm{rad})$ & $9 / 657$ & $2.0 / 140$ & $18 \%$ & $r, \quad M A E$, \\
\hline 33 & ANFIS & Tair, H & $15 / 400$ & $? / ?$ & $0 \%$ & RMSE \\
\hline 34 & MLR & $\begin{array}{l}\text { H, Tair, Tc, } \operatorname{lag}(\mathrm{H}), \\
\operatorname{lag} \text { (Tair), } \operatorname{lag}(\mathrm{Tc})\end{array}$ & $7 / 2555$ & $2.0 / 730$ & $22 \%$ & $M E, \sigma_{\epsilon}, R^{2}$ \\
\hline 35 & $\mathrm{NN}$ & $\begin{array}{l}\text { H, Tair, Tc, } \operatorname{lag}(\mathrm{H}) \text {, } \\
\text { lag(Tair), } \operatorname{lag}(\mathrm{Tc})\end{array}$ & $7 / 2555$ & $2.0 / 730$ & $22 \%$ & $M E, \sigma_{\epsilon}, R^{2}$ \\
\hline 36 & PCA, & H, Tair, $\mathrm{P}$ & $4.2 / 1525$ & $0.1 / 30$ & $2 \%$ & - \\
\hline 37 & PCA, & H, Tair, P & $3 / 900$ & $0.2 / 56$ & $6 \%$ & - \\
\hline 38 & $\begin{array}{l}\mathrm{SVM} \\
\mathrm{NN}\end{array}$ & $\begin{array}{l}\mathrm{t}, \quad \mathrm{H}, \quad \text { Tair, } \\
\operatorname{mav} \text { (Tair) }\end{array}$ & $14 / ?$ & $2.0 / ?$ & $13 \%$ & $r, R^{2}, \sigma_{\epsilon}$ \\
\hline 39 & GRAD & H, S, t, IRF(Tair, Tw) & $12 / ?$ & $0.0 /$ & $0 \%$ & $\sigma_{\epsilon}$ \\
\hline 40 & SLICE & H, S, t, IRF(Tair, Tw) & $12 / ?$ & $0.0 /$ & $0 \%$ & $\sigma_{\epsilon}$ \\
\hline 41 & HTT & $\mathrm{H}, \mathrm{S}, \mathrm{Tc}$ & $3.2 / 169$ & $0.4 / 20$ & $11 \%$ & $R_{a d j}^{2}, \sigma_{\epsilon}, p d f(\varepsilon)$ \\
\hline 42 & ECM & $\mathrm{H}, \mathrm{S}, \mathrm{Tc}, \mathrm{e}(\mathrm{t}-1)$ & $3.2 / 169$ & $0.4 / 20$ & $11 \%$ & $R_{a d j}^{2}, \sigma_{\epsilon}, p d f(\varepsilon)$ \\
\hline 43 & NN & $\mathrm{H}, \mathrm{S}, \mathrm{t}$ & $? / 429$ & $0.0 /$ & $0 \%$ & $\sigma_{\epsilon}, M S E$ \\
\hline 44 & $\mathrm{IRF}+\mathrm{NN}$ & $\begin{array}{l}\mathrm{H}, \mathrm{S}, \mathrm{t}, \text { Tair, } \operatorname{IRF}(\mathrm{P}) \text {, } \\
\operatorname{IRF}(\mathrm{M})\end{array}$ & $? / ?$ & $0.0 /$ & $0 \%$ & $R^{2}$ \\
\hline 45 & NN & $\mathrm{H}, \mathrm{s}, \mathrm{t}, \mathrm{IRF}$ (Tair) & $? / ?$ & $0.0 /$ & $0 \%$ & $\sigma_{\epsilon}$ \\
\hline 46 & HSTT & $\mathrm{H}, \mathrm{S}, \mathrm{t}, \mathrm{IRF}$ (Tair) & $? / ?$ & $0.0 /$ & $0 \%$ & $\sigma_{\epsilon}$ \\
\hline
\end{tabular}

Continued on next page 


\begin{tabular}{|c|c|c|c|c|c|c|}
\hline \multirow{2}{*}{\multicolumn{7}{|c|}{ Validation set }} \\
\hline & & & Training set & Validation set & \% Test & Error metric \\
\hline 47 & $\mathrm{NN}$ & $\mathrm{H}, \mathrm{Hd}, \operatorname{lag}(\mathrm{P})$ & $1.1 / 58$ & $0.4 / 18$ & $24 \%$ & $R^{2}$ \\
\hline 48 & $\mathrm{NN}$ & $\mathrm{H}, \mathrm{Tc}$ & $22 / 8120$ & $0.3 / 62$ & $1 \%$ & $p d f(\varepsilon)$, \\
\hline 49 & NARXNN & $\mathrm{H}, \operatorname{lag}(\mathrm{H}), \operatorname{lag}($ out $)$ & $22 / 8120$ & $0.3 / 62$ & $1 \%$ & $\begin{array}{l}M S E \\
R^{2},\end{array}$ \\
\hline 50 & AANN & $\operatorname{lag}(\mathrm{rad})$ & $22 / 8120$ & $0.3 / 62$ & $1 \%$ & $\begin{array}{l}M R^{2}, \\
{ }^{2},\end{array}$ \\
\hline 51 & HTT & $\mathrm{H}, \mathrm{Tc}$ & $5 / 95$ & $0.0 /$ & $0 \%$ & $\begin{array}{l}M S E \\
R_{a d j}^{2}, \sigma_{\epsilon}, \quad \varepsilon_{\max }, \\
\varepsilon_{\min }, S S E\end{array}$ \\
\hline 52 & PCA, RR & $\mathrm{H}$ & $6 / 4380$ & $0.0 /$ & $0 \%$ & - \\
\hline 53 & MLR & $\mathrm{H}, \mathrm{Tc}$, Tair, $\mathrm{P}, \mathrm{t}$ & $6 / 2550$ & $1.0 / 365$ & $13 \%$ & $R_{a d j}^{2}, R M S E$ \\
\hline 54 & $\mathrm{NN}$ & $\mathrm{Hd}, \operatorname{lag}(\mathrm{Hd})$ & $8 / 163$ & $1.0 / 20$ & $11 \%$ & $r, \quad r^{2}, \quad M S E$, \\
\hline 55 & MLR & $\mathrm{Hd}, \operatorname{lag}(\mathrm{Hd})$ & $8 / 163$ & $1.0 / 20$ & $11 \%$ & $r, M S E, M A E$ \\
\hline 56 & NN & H, Tair, d(H), d(Tair) & $25.5 / 918$ & $3.0 / 103$ & $10 \%$ & $R M S E$ \\
\hline 57 & $\begin{array}{l}\text { NN, } \\
\text { MARS, } \\
\text { RF, BRT, }\end{array}$ & $\begin{array}{l}\mathrm{H}, \text { Tair, } \mathrm{S}, \mathrm{t}, \operatorname{mav}(\mathrm{H}) \text {, } \\
\operatorname{mav}(\text { Tair }), \mathrm{P}, \mathrm{d}(\mathrm{H})\end{array}$ & $18 / 600$ & $10.0 / 400$ & $40 \%$ & $M A E, A R V$ \\
\hline 58 & $\begin{array}{l}\text { SVM } \\
\text { SVM }\end{array}$ & $\begin{array}{l}\mathrm{H}, \mathrm{Hd}, \operatorname{lag}(\mathrm{H}), \operatorname{lag}(\mathrm{Hd}), \\
\operatorname{lag}(\text { out })\end{array}$ & $11 / 573$ & $3.0 / 156$ & $21 \%$ & $r, M A E, M S E$ \\
\hline & $\begin{array}{l}=\text { neu } \\
\text { therm } \\
\text { pal co } \\
\text { therm } \\
\text { auto-a } \\
\text { regres: } \\
\text { upstre } \\
\text { Tair = } \\
\text { lag }(\cdot) \\
\text { movin }\end{array}$ & $\begin{array}{l}\text { liew summary }(2) . \text { Models } \\
\text { function; HST }=\text { hydrosta } \\
\text { al networks; NARX }=\text { non } \\
\text { l time; HYB }=\text { hybrid; A } \\
\text { pponent analysis; SVM = s } \\
\text { lime; NARXNN = non-lin } \\
\text { sociative neural network; R } \\
\text { on splines; RF = random } \\
\text { m pool level; S = season; } \\
\text { air temperature; Tw = wat } \\
=\text { lagged variable; } d(\cdot)=\mathrm{d} \\
\text { average; Hd = downstream }\end{array}$ & $\begin{array}{l}\text { linear autoreg } \\
\text { FIS = adapti } \\
\text { pport vector } \\
\text { ar autoregress } \\
=\text { robust reg } \\
\text { rest; BRT }= \\
=\text { time; } \mathrm{d}= \\
\text { r temperatur } \\
\text { ivative; } \mathrm{P}= \\
\text { pool level }\end{array}$ & $\begin{array}{l}\text { neal regression } \\
\text { KNN = k-nea } \\
\text { sive exogenous; } \\
\text { neuro-fuzzy sys } \\
\text { hine; HSTT }= \\
\text { exogenous neur } \\
\text { sion; MARS }= \\
\text { sted regression } \\
\text { ivative; Tc }=\mathrm{c} \\
R F(\cdot)=\text { impul } \\
\text { cipitation; out }\end{array}$ & $\begin{array}{l}\mathrm{F}=\text { in } \\
\text { neighb } \\
\mathrm{T}=\text { hy } \\
\text { PCA } \\
\text { lostatic } \\
\text { etwork; } \\
\text { ivariate } \\
\text { es. Inp } \\
\text { ete tem } \\
\text { esponse } \\
\text { utput; }\end{array}$ & $\begin{array}{l}\text { ulse re- } \\
\text { urs; NN } \\
\text { rostatic } \\
\text { princi- } \\
\text { easonal } \\
\text { ANN = } \\
\text { idaptive } \\
\text { s: H H = } \\
\text { erature; } \\
\text { unction; } \\
\text { av }(\cdot)=\end{array}$ \\
\hline
\end{tabular}

\subsection{Input selection}

In previous sections, it was pointed out that the model performance depended on the predictor variables considered. The range of options for variable selection is wide. Most of the papers reviewed do not use any specific method for variable selection, apart from "a priori knowledge" (e.g. [47]) or trial and error (e.g. [42]).

This issue has arisen in combination with the use of NN [42], [61], [27], [41], [52], NARX [38], [52], MLR [26] and ANFIS models [47].

First, the selection is limited by the available data. While the reservoir level and the temperature are usually measured at the dam site, other potentially influential variables, such as precipitation, are frequently not available. 
One of the advantages of HST method is that only the reservoir level is required.

Second, it must be decided whether or not to use the lagged values of the target variable for prediction. The consequences of making predictions from the output itself have already been mentioned, regardless whether the observed or the estimated previous value is used. It can be concluded that the AR models prioritise prediction accuracy over model interpretation.

Third, the possibility of adding derived variables (and which ones), such as moving averages and gradients, can be considered. They can be set beforehand, on the basis of engineering judgement, or selected by means of some performance criterion from a wide set of variables.

Finally, consideration should be given to include non-causal variables in the model. For example, is it appropriate to base the prediction of radial displacements at a given location on the displacement recorded at another point of the dam? Will it improve the model accuracy? What consequences would it have in the interpretation of the results?

Some models like the HST are often used with a set of specific predictors, and therefore variable selection is restricted to the order of the polynomial of the reservoir level, and the shape of the time dependent functions. The opposite case is the NARX method, which can be used with a high amount of predictor variables.

Hence, the criterion to be used depends on the type of data available, and the characteristics of the phenomenon to be modelled. Again, engineering judgement is essential to make these decisions.

The selection of predictors may be useful to reduce the dimensionality of the problem (essential for NARX models), as well as to facilitate the interpretation of the results. PCA can be used for this purpose [24], as well as AANN [52]. Some specific methods for variable selection in dam monitoring analysis have been proposed, by means of backward elimination [33] genetic algorithms (GA) [26], and singular spectrum analysis (SSA) [52], although the vast majority of authors applied trial and error or engineering judgement.

\subsection{Model interpretation}

The main interest of this work focuses on model accuracy: a more accurate predictive model allows defining narrower thresholds, and therefore reducing the number of false anomalies. Nonetheless, once a value above (or below, if

appropriate) the warning threshold is registered, an engineering analysis of 
the situation is needed to assess its seriousness, for which the ability of the model to interpret dam behaviour may be useful.

The HST method has been traditionally used to identify the effect on the response of the dam of each considered action: hydrostatic load, temperature and time (e.g. [12]). However, it is clear that this analysis is only valid if the predictor variables are independent, which is not generally true [3], [17].

On the contrary, the ability of NN and similar models for interpreting dam behaviour is often neglected. They are frequently termed "black box" models, in reference to its lack of interpretability.

It turns out that NN models are well suited to capture complex interactions among inputs, and non-linear input-output relations. If an NN model offers a much better accuracy than HST for a given phenomenon, it is probable that it does not fulfil the hypothesis of HST (input independence, linearity). Hence, it would be more appropriate to extract information on the dam behaviour from the interpretation of the NN model.

The effect of each predictor can be analysed by means of computing the response of the NN model to a set of simulated data distributed along the range of variation of the variable under consideration, while keeping the rest at constant values (ceteris paribus, [12]). They can be set either to the correspondent mean or to several other values, in order to gain more detailed information on the dam response. Analyses of this kind can be found in the literature: Mata [12] calculated the effect of the reservoir level on the radial displacements of an arch dam for each season of the year, and the effect of temperature when setting the pool level at several constant values. Similar studies are due to Santillán et al. [66], Simon et al. [11] and Popovici et al. [30].

More complex algorithms have been proposed in related fields to unveil the relevance of each input in NN models (see for example [67], [68] and [69]), which may be helpful in dam monitoring.

Therefore, even though NN and similar models must be interpreted with great care, their ability to extract information on the dam behaviour should not be underestimated.

\subsection{Training and validation sets}

It is common and convenient to divide the available data into two subsets: the training set is used to adjust the model parameters, whereas the valida- 
tion set is solely used to measure the prediction accuracy ${ }^{5}$. In statistics, this need is well known, since it has been proven that the prediction accuracy of a predictive model, measured on the training data, is an overestimation of its overall performance [70]. Any subsetting of the available data into training and validation sets is acceptable, provided the data are independent and identically distributed (i.i.d.). This is not the case in dam monitoring series, which are time-dependant in general.

The amount of available data is limited, what in turn limits the size of the training and validation samples. It is convenient that both training and validation data cover all the range of variation of the most influential variables. It is not infrequent that reservoir level follows a relatively constant yearly cycle by which situations from the lowest to the highest pool level are presented each year. Temperature, which is the second most influential variable on average, responds to a more defined annual cycle. As a consequence, many authors measure the size of the training and validation sets in years.

Moreover, dam behaviour models are used in practice to calculate the future response, on the basis of the observed, normal functioning, and draw conclusions about the safety state. Therefore, it seems reasonable to estimate the model accuracy with a similar scheme, i.e., to take the most recent data as the validation set. This is the procedure used in the vast majority of the reviewed papers (38/39), with the unique exception of Santillán et al. [33], who made a random division of the data.

Models based on the underlying physics of the phenomenon and those with fewer parameters (HST, IRF and MLR), are less prone to over-fitting. As a result, a higher value can be given to the training error. This is probably the reason why most studies do not consider a validation set, but rather use all the data for the model fit e.g. [34], [24] (Figure 6 (a))

When a validation set is used, $10 \%$ of the available data is reserved for that purpose on average. The higher frequency observed around $20 \%$ corresponds to the papers dealing with the data from the 6th ICOLD Benchmark Workshop, where the splitting criterion was fixed by the organisers.

Tayfur et al. [5] reserved only one year for training, but explicitly mentioned that it contained all the range of variation of the reservoir level. Some authors proposed to set a minimum of 5 to 10 observations per model pa-

\footnotetext{
${ }^{5}$ the terminology is not universal; the data which is not used to fit the model is sometimes called test or prediction set.
} 
rameter to estimate [1].

NN, ANFIS, SVM, NARX $\quad$ HST, MLR, IRF
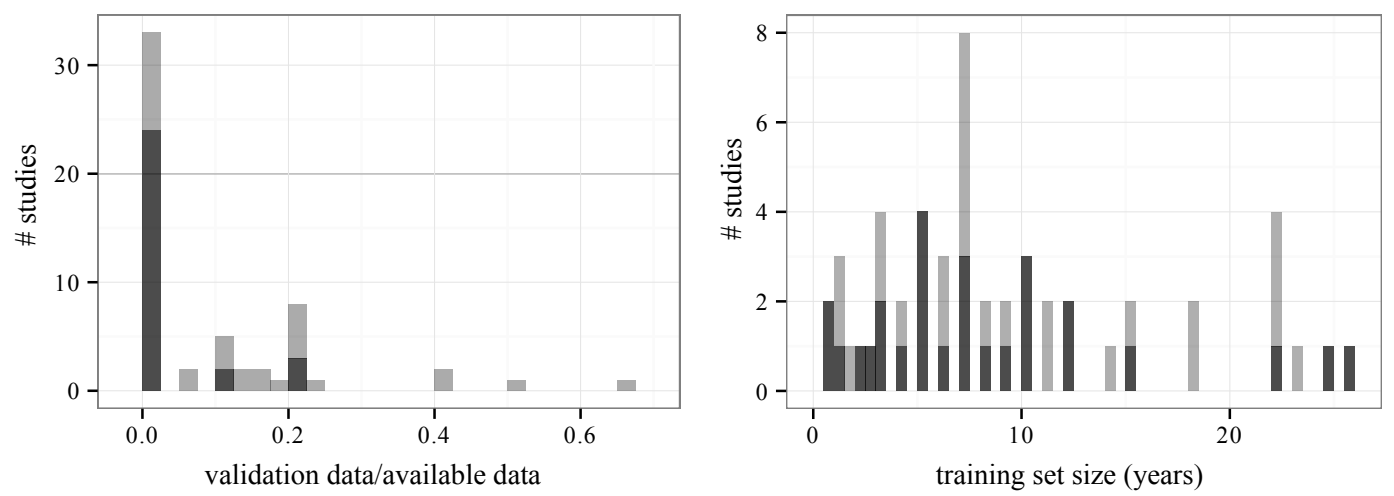

Figure 6: Training and validation sets in the papers reviewed. Left: ratio of validation data with respect to available data. Rigth: training set size (years)

A fundamental premise for the successful implementation of any prediction model is that the training data correspond to a period in which the dam has not undergone changes in its behaviour. In practice, it is not easy to ensure that this condition is fulfilled. While the history of mayor repairs and events is usually available, it is well known that the behaviour in the first years of operation usually corresponds to a transient state, which may not be representative of its response in normal operation afterwards [3]. Therefore, the use of data corresponding to the first period to adjust the model parameters may lead to an increase in prediction error. Lombardi [3] estimated that 12 years from dam construction are required for a data-based model to be effective.

This issue can be checked by analysing the training error: ideally, errors shall be independent, with zero mean and constant variance [1]. Some authors compute some of these values for evaluating the goodness of fit (e.g. [11], [64], [42]).

On another note, a minimum amount of data is necessary to build a predictive model with appropriate generalisation ability. De Sortis and Paoliani [59] run a sensitivity analysis of the prediction error as a function of the training set size. They concluded that 10 years were necessary for obtaining stable results. For his part, Chouinard and Roy [13] performed a similar work on a dam set. Provided that most of them were run-of-the-river small dams, which remained full most of the time, the thermal effect was the pre- 
ponderant variable. As this is almost constant every year, 5 years of data were enough for most cases to achieve high accuracy.

According to the Swiss Comittee on Dams [1], a minimum of "5 yearly cycles" should be available, what suggests that they refer to filling-emptying cycles throughout a year (to account for the thermal variation). On the contrary, ICOLD [2] recommended to set thresholds as a function of the prediction error along "2 or 3 years of normal operation".

The authors performed a similar analysis for 14 instruments in an arch dam [58], and reported that the prediction accuracy was higher in some cases for models trained over the most recent 5 years of data (the maximum training set length was 18 years).

The size of the validation set ranges from 1 to 25 years (Figure 6 (b)), and depends on the amount of data available, rather than on the type of model.

Again, engineering judgement is essential to assess the appropriateness of the train and validation sets, as well as to assess the model performance. Both subsets should cover the whole range of variation of the most influential variables, and belong to the same density function.

Such verifications are not performed in general in dam monitoring analyses, probable due to a) the number of data available at a given time cannot be arbitrarily increased, and b) the validation data shall be the most recent. In practice, there is not agreement on the appropriate criterion to define training and validation sets, which depends on the available data. Consequently, the comparison between models which predict different variables has limited reliability, although it is sometimes considered [26], [41].

\subsection{Prediction accuracy measurement}

It is very important to appropriately estimate the prediction error of a model, since a) it provides insight into its accuracy, b) it allows comparing different models, and c) it is used to define warning thresholds.

There are various error measures to assess how well a model matches the

observed data, among which the most commonly used are included in Table 3 .

The result of using any of these indexes is frequently equivalent when referred to a given prediction task: the more accurate model will have a smaller $R M S E$ value, but also the lowest $M S E$, and higher $r$ and $R^{2}$. However, they also present differences which can be relevant, and are often not considered. 
Mean squared error

Root mean squared error

Mean absolute error

Correlation coefficient

Coefficient of determination

Standard error of estimate

Mean absolute percentage error

Maximum absolute error

Adjusted $R^{2}$

Sum of squared error

Average relative variance

Mean error
$M S E=\frac{\sum_{i=1}^{N}\left(y_{i}-F\left(x_{i}\right)\right)^{2}}{N}$

$R M S E=\sqrt{\frac{\sum_{i=1}^{N}\left(y_{i}-F\left(x_{i}\right)\right)^{2}}{N}}=\sqrt{M S E}$

$M A E=\frac{1}{N} \sum_{i=1}^{N}\left|y_{i}-F\left(x_{i}\right)\right|$

$r=\frac{\sum_{i=1}^{N}\left(y_{i}-\bar{y}\right)\left(F\left(x_{i}\right)-\overline{F\left(x_{i}\right)}\right)}{\left(\sum_{i=1}^{N}\left(y_{i}-\bar{y}\right)^{2}\right)^{0.5}\left(\sum_{i=1}^{N}\left(F\left(x_{i}\right)-\overline{F\left(x_{i}\right)}\right)\right)^{0.5}}$

$R^{2}=1-\frac{\sum_{i=1}^{N}\left(y_{i}-F\left(x_{i}\right)\right)^{2}}{\sum_{i=1}^{N}\left(y_{i}-\bar{y}\right)^{2}}$

$\sigma_{\varepsilon}=\sqrt{\frac{\sum\left(y_{i}-f\left(x_{i}\right)\right)^{2}}{N}}$

$M A P E=\frac{100}{N} \sum_{i=1}^{N}\left|\frac{y_{i}-F(x)}{y_{i}}\right|$

$\operatorname{Max} A E=|\varepsilon|_{\max }$

$R_{a d j}^{2}=R^{2}-\left(1-R^{2}\right) \frac{p}{N-p-1}$

$S S E=\sum_{i=1}^{N}\left(y_{i}-F\left(x_{i}\right)\right)^{2}$

$A R V=\frac{\sum_{i=1}^{N}\left(y_{i}-F\left(x_{i}\right)\right)^{2}}{\sum_{i=1}^{N}\left(y_{i}-\bar{y}\right)^{2}}=\frac{M S E}{\sigma^{2}}=1-R^{2}$

$M E=\frac{1}{N} \sum_{i=1}^{N}\left(y_{i}-F\left(x_{i}\right)\right)$

Table 3: Measures of accuracy

Provided that $M S E=(R M S E)^{2}$, they can be used indistinctly for model comparison. The only difference is that $R M S E$ is measured in the same units as the target variable, so its value is more intuitive on the model accuracy. It should be noted that they are computed on the basis of the squared residuals, therefore they are sensitive to the presence of outliers, i.e., a few large prediction errors. In this sense, $M A E$ could be considered a better choice, provided that it shares the advantage of $R M S E$ (it is measured in the same units as the output), and not its drawback. Mindful of this fact, both can be used interchangeably, if the analysis is complemented with a graphical exploration of the model fit, and/or other error measures.

The drawback to both $M S E$ and $R M S E$ is that they are not suitable for comparing models fitting different variables, provided that they do not 
consider neither the mean nor the deviation of the output.

This limitation can be overcome by using the correlation coefficient $r$, since $r \in[-1,1]$. On the contrary, it is not exactly an error rate, but rather an index of the strength of the linear relationship between observations and predictions. In other words, it indicates to what extent one variable increases as the other does, and vice versa. It can be checked that the value of $r$ for a prediction calculated as $\hat{Y}=A Y+B$ is equal to 1 , while the error can be very large and will generally be non-zero (unless $A=1$ and $B=0$ ) [71]. As an example, Rankovic et al. [41] considered $r$ and $r^{2}$, as well as $M A E$ and $M S E$. While the results were similar for the training and validation sets in terms of $r$ and $r^{2}$, both $M A E$ and $M S E$ were much greater in the validation set (as much as 7 times grater). These results may reflect some degree of over-fitting.

If $r$ is used as a measure of goodness of fit, its value always increases with increasing number of model parameters (except in the highly unlikely event that the functions are completely independent of output). To take into account the number of parameters of each, the $R_{a d j}$ parameter can be used (e.g. [26], [64]).

As an alternative, $R^{2}$, or its equivalent $A R V$ can be chosen. They have the advantage over the correlation coefficient of being sensitive to differences in the means and variances of observations and predictions, while maintaining the ability to compare models fitted to different data [58].

Finally, it should be noted that the reading error of the devices may be relevant when predictions of variables of different nature are compared, although it is often not taken into account. It cannot be expected to obtain a model with an error below the measurement resolution [14]. Popovici et al. [30] reported that the overall accuracy of NN models was lower for tangential than for radial displacements, and attributed it to the lower range of variation of the former. It is possible that the reading error (which in principle should be the same for tangential and radial displacements) were relevant in the first case and negligible in the second.

The authors found that models with relatively high $A R V$ corresponded with very low $M A E$, close to the measurement error [58].

Measurement error $\left(\varepsilon_{r}\right)$ should always be considered for evaluating model accuracy. One possibility would be to neglect the errors below that value before computing the prediction accuracy, by means of substituting $\left(y_{i}-F\left(x_{i}\right)\right)$ by $\left|y_{i}-F\left(x_{i}\right)\right|-\varepsilon_{r}$, in the calculation of $M S E, R M S E, r$ and $R^{2}$. Similarly, $M A E$ should be computed as: 


$$
M A E^{*}=\frac{1}{N} \sum_{i=1}^{N}\left(\left|y_{i}-F\left(x_{i}\right)\right|-\varepsilon_{r}\right)
$$

It is convenient to compute more than one error rate, especially if the aim is to compare models predicting variables of different kind. In addition, a graphical analysis of the error is highly advisable.

\section{Conclusions}

There is a growing interest in the application of innovative tools in dam monitoring data analysis. Although only HST is fully implemented in engineering practice, the number of publications on the application of other methods has considerably increased in recent years.

NN are by far the most frequently used ML technique, which has been applied to a great variety of problems: displacements, leakage, crown settlement, crack opening, etc. Other tools are less frequent, and restricted to specific cases so far.

It seems clear that the models based on ML algorithms can offer more accurate estimates of the dam behaviour than the HST method in many cases. In general, they are more suitable to reproduce non-linear effects and complex interactions between input variables and dam response.

On the contrary, they must be employed rigorously. Given their high number of parameters and their flexibility, they are susceptible to over-fit the training data. It is thus essential to check their generalisation capability on an adequate validation data set, not used for fitting the model parameters.

Regardless of the technique used, engineering judgement based on experience is critical for building the model, for interpreting the results, and for decision making with regard to dam safety.

\section{Acknowledgements}

The research has been partially supported by the Spanish Ministry of Economy and Competitiveness (Ministerio de Economía y Competitividad, MINECO) through the projects iComplex (IPT-2012-0813-390000) and AIDA (BIA2013-49018-C2-1-R and BIA2013- 49018-C2-2-R). 


\section{References}

[1] Swiss Committee on Dams (2003). Methods of analysis for the prediction and the verification of dam behaviour. Technical report, ICOLD.

[2] International Commission on Large Dams (2012). Dam surveillance guide. Technical Report B-158, ICOLD.

[3] G. Lombardi (2004). Advanced data interpretation for diagnosis of concrete dams. Technical report, CISM.

[4] G. Lombardi, F. Amberg, G. Darbre (2008). Algorithm for he prediction of functional delays in the behaviour of concrete dams. Hydropower and Dams, (3):111-116.

[5] G. Tayfur, D. Swiatek, A. Wita, V. P. Singh (2005). Case study: Finite element method and artificial neural network models for flow through jeziorsko earthfill dam in poland. Journal of Hydraulic Engineering, 131(6):431440.

[6] F. Restelli (2010). Systemic evaluation of dam monitoring using PCA. In Proceedings of the Sixth Argentinian Conference on Dams. Neuquén, Argentina. [in Spanish].

[7] F. Restelli (2013). Systemic evaluation of the response of large dams instrumentation. Application at El Chocón dam. In Proceedings of the 9th ICOLD European Club Symposium. Venice, Italy.

[8] T. Hastie, R. Tibshirani, J. Firedman (2009). The Elements of Statistical Learning - Data Mining, Inference, and Prediction, Second Edition. Springer, 2 edition.

[9] G. Willm, N. Beaujoint (1967). Les mthodes de surveillance des barrages au service de la production hydraulique d'electricit de france-problmes ancients et solutions nouvelles. In 9th ICOLD Congres, pages Q34-R30, 529-550. [in French].

[10] S. Bonelli, H. Félix (2001). Delayed response analysis of temperature effect. In Proceedings of the Sixth ICOLD Benchmark Workshop on Numerical Analysis of Dams. Salzburg, Austria. 
[11] A. Simon, M. Royer, F. Mauris, J. Fabre (2013). Analysis and interpretation of dam measurements using artificial neural networks. In Proceedings of the 9th ICOLD European Club Symposium. Venice, Italy.

[12] J. Mata (2011). Interpretation of concrete dam behaviour with artificial neural network and multiple linear regression models. Engineering Structures, 3(3):03 - 910. ISSN 141-0296. doi: 10.1016/j.engstruct.2010.12.011.

[13] L. Chouinard, V. Roy (2006). Performance of statistical models for dam monitoring data. In Joint International Conference on Computing and Decision Making in Civil and Building Engineering, Montreal, pages 1416.

[14] H. Yu, Z. Wu, T. Bao, L. Zhang (2010). Multivariate analysis in dam monitoring data with PCA. Science China Technological Sciences, 53(4):1088-1097. ISSN 1674-7321, 1862-281X. doi:10.1007/s11431-0100060-1.

[15] A. Carrère, C. Noret-Duchêne (2001). Interpretation of an arch dam behaviour using enhanced statistical models. In Proceedings of the Sixth ICOLD Benchmark Workshop on Numerical Analysis of Dams. Salzburg, Austria.

[16] M. Tatin, M. Briffaut, F. Dufour, A. Simon, J. Fabre (2013). Thermal displacements of concrete dams: Finite element and statistical modelling. In Proceedings of the 9th ICOLD European Club Symposium. Venice, Italy.

[17] A. F. Silva Gomes, D. Silva Matos (1985). Quantitative analysis of dam monitoring results. state of the art, applications and prospects. In 15th ICOLD Congres, pages Q56-R39, 319-334.

[18] P. Léger, M. Leclerc (2007). Hydrostatic, temperature, timedisplacement model for concrete dams. Journal of engineering mechanics, 133(3):267277.

[19] L. Chouinard, D. Bennett, N. Feknous (1995). Statistical analysis of monitoring data for concrete arch dams. Journal of Performance of Constructed Facilities, 9(4):286-301. ISSN 0887-3828. doi: 10.1061/(ASCE)0887-3828(1995)9:4(286). 
[20] F. Amberg (2009). Interpretative models for concrete dam displacements. In 23th ICOLD Congres, pages Q91-RXXX, XXX-XXX.

[21] I. Penot, B. Daumas, J. Fabre (2005). Monitoring behaviour. Water Power and Dam Construction.

[22] J. Fabre, G. Geffraye (2013). Estudio y control de los desplazamientos trmicos de la presa gage II (francia) por aportacin de dispositivos especiales de calefaccin y enfriamiento. San Juan.

[23] F. Breitenstein, W. Klher, R. Widman (1985). Safety control of the dams of the glockner-kaprun hydro-electric development. In 15 Congreso Internacional de Grandes Presas, pages Q56-R59, 1121-1134.

[24] J. Mata, A. Tavares de Castro, J. S da Costa (2014). Constructing statistical models for arch dam deformation. Structural control health monitoring, 21(3):423-437. doi:10.1002/stc.1575.

[25] Q. Guedes, P. Coelho (1985). Statistical behaviour model of dams. In 15th ICOLD Congres, pages Q56-R16, 319-334.

[26] B. Stojanovic, M. Milivojevic, M. Ivanovic, N. Milivojevic, D. Divac (2013). Adaptive system for dam behavior modeling based on linear regression and genetic algorithms. Advances in Engineering Software, 65:182190.

[27] S. Demirkaya, M. Balcilar (2012). The contribution of soft computing techniques for the interpretation of dam deformation. Rome, Italy.

[28] S. Bonelli, K. Radzicki (2008). Impulse response function analysis of pore pressure in earthdams. European Journal of Environmental and Civil Engineering, 12(3):243-262.

[29] F. J. Sánchez Caro (2007). Dam safety: contributions to the deformation analysis and monitoring as an element of prevention of pathologies of geotechnical origin. Ph.D. thesis, UPM. [In Spanish].

[30] I. C. Popovici, A., T. Ayvaz (2013). The performance of the neural networks to model some response parameters of a buttress dam to environment actions. In Proceedings of the 9th ICOLD European Club Symposium. Venice, Italy. 
[31] O. Crépon, M. Lino (1999). An analytical approach to monitoring. Water Power and Dam Construction.

[32] G. Zenz, P. Obernhuber (2001). Icold benchmark workshops on dam safety. Hydropower and Dams, (2):75-78.

[33] D. Santillán, J. Fraile-Ardanuy, M. Toledo (2014). Seepage prediction in arch dams by means of artificial neural networks. Water Technology and Science, V(3). [in Spanish].

[34] S. Bonelli, P. Royet (2001). Delayed response analysis of dam monitoring data. In Proceedings of the Fifth ICOLD European Symposium on Dams in a European Context. Geiranger, Norway.

[35] F. Riquelme, J. Fraile, D. Santillán, R. Morán, M. Toledo (2011). Application of artificial neural network models to determine movements in an arch dam. In Proceedings of the 2nd International Congress on Dam Maintenance and Rehabilitation, pages 117-123. Zaragoza, Spain.

[36] P. Palumbo, L. Piroddi, S. Lancini, F. Lozza (2001). Narx modeling of radial crest displacements of the schlegeis arch dam. In Proceedings of the Sixth ICOLD Benchmark Workshop on Numerical Analysis of Dams. Salzburg, Austria.

[37] B.-J. Chen, M.-W. Chang, et al. (2004). Load forecasting using support vector machines: A study on eunite competition 2001. Power Systems, IEEE Transactions on, 19(4):1821-1830.

[38] L. Piroddi, W. Spinelli (2003). Long-range nonlinear prediction: a case study. In Decision and Control, 2003. Proceedings. 42nd IEEE Conference on, volume 4, pages 3984-3989. IEEE.

[39] C. M. Bishop (1995). Neural networks for pattern recognition. Oxford university press.

[40] R. S. Govindaraju (2000). Artificial neural networks in hydrology. ii: hydrologic applications. Journal of Hydrologic Engineering, 5(2):124137.

[41] V. Ranković, A. Novaković, N. Grujović, D. Divac, N. Milivojević (2014). Predicting piezometric water level in dams via artificial neural networks. Neural Computing and Applications, 24(5):1115-1121. 
[42] C.-Y. Kao, C.-H. (2013). Monitoring of long-term static deformation data of fei-tsui arch dam using artificial neural network-based approaches. Structural Control and Health Monitoring, 20(3):282-303.

[43] H. Ruiz (2013). Fisher networks: a principled approach to retrieval-based classification. Ph.D. thesis, Liverpool John Moores University.

[44] J.-S. Jang (1993). Anfis: adaptive-network-based fuzzy inference system. Systems, Man and Cybernetics, IEEE Transactions on, 23(3):665-685.

[45] T. Takagi, M. Sugeno (1985). Fuzzy identification of systems and its applications to modeling and control. Systems, Man and Cybernetics, IEEE Transactions on, (1):116-132.

[46] L. Opyrchal (2003). Application of fuzzy sets method to identify seepage path through dams. Journal of Hydraulic Engineering, 129(7):546-548.

[47] V. Ranković, N. Grujović, D. Divac, N. Milivojević, A. Novaković (2012). Modelling of dam behaviour based on neuro-fuzzy identification. Engineering Structures, 35:107113. doi:10.1016/j.engstruct.2011.11.011.

[48] H. Xu, X. Li (2012). Inferring rules for adverse load combinations to crack in concrete dam from monitoring data using adaptive neuro-fuzzy inference system. Science China Technological Sciences, 55(1):136141.

[49] S. Demirkaya (2010). Deformation analysis of an arch dam using ANFIS. In Proceedings of the second international workshop on application of artificial intelligence and innovations in engineering geodesy. Braunschweig, Germany, page 2131.

[50] L. Cheng, D. Zheng (2013). Two online dam safety monitoring models based on the process of extracting environmental effect. Advances in Engineering Software, 57:4856.

[51] B. Nedushan (2002). Multivariable statistical analysis of monitoring data for concrete dams. Ph.D. thesis, McGill University.

[52] C.-H. Loh, C.-H. Chen, T.-Y. Hsu (2011). Application of advanced statistical methods for extracting long-term trends in static monitoring data from an arch dam. Structural Health Monitoring, 10(6):587-601. 
[53] I.-S. Jung, M. Berges, J. H. G. Jr, C. J. Kelly (2013). Interpreting the dynamics of embankment dams through a time-series analysis of piezometer data using a non-parametric spectral estimation method. In Computing in Civil Engineering (2013), page 2532. ASCE.

[54] A. J. Smola, B. Schlkopf (2004). A tutorial on support vector regression. Statistics and computing, 14(3):199222.

[55] V. Ranković, N. Grujović, D. Divac, N. Milivojević (2014). Development of support vector regression identification model for prediction of dam structural behaviour. Structural Safety, 48:33-39.

[56] V. Saouma, E. Hansen, B. Rajagopalan (2001). Statistical and 3d nonlinear finite element analysis of schlegeis dam. In Proceedings of the Sixth ICOLD Benchmark Workshop on Numerical Analysis of Dams, pages 17-19.

[57] C. Xu, D. Yue, C. Deng (2012). Hybrid GA/SIMPLS as alternative regression model in dam deformation analysis. Engineering Applications of Artificial Intelligence, 25(3):468475.

[58] F. Salazar, M. Toledo, E. Oñate, R. Morán (2014). An empirical comparison of machine learning techniques for dam behaviour modelling. Structural Safety, submitted.

[59] A. De Sortis, P. Paoliani (2007). Statistical analysis and structural identification in concrete dam monitoring. Engineering structures, 29(1):110-120.

[60] H.-z. Su, Z.-r. Wu, Z.-p. Wen (2007). Identification model for dam behavior based on wavelet network. Computer-Aided Civil and Infrastructure Engineering, 22(6):438-448.

[61] A. Panizzo, A. Petaccia (2009). Analysis of monitoring data for the safety control of dams using neural networks. In New Trends in Fluid Mechanics Research, page 344347. Springer.

[62] S. Bonelli, K. Radzicki, et al. (2007). The impulse response function analysis of pore pressures monitoring data. In 5th International Conference on Dam Engineering. 
[63] F. Perner, P. Obernhuber (2010). Analysis of arch dam deformations. Frontiers of Architecture and Civil Engineering in China, 4(1):102-108.

[64] F. Li, Z. Wang, G. Liu (2013). Towards an error correction model for dam monitoring data analysis based on cointegration theory. Structural Safety, 43:1220.

[65] V. Nourani, A. Babakhani (2012). Integration of artificial neural networks with radial basis function interpolation in earthfill dam seepage modeling. Journal of Computing in Civil Engineering, 27(2):183-195.

[66] D. Santillan, J. Fraile-Ardanuy, M. Toledo (2013). Dam seepage analysis based on artificial neural networks: The hysteresis phenomenon. In Neural Networks (IJCNN), The 2013 International Joint Conference on, pages 1-8. IEEE.

[67] P. Cortez, M. J. Embrechts (2011). Opening black box data mining models using sensitivity analysis. In Computational Intelligence and Data Mining (CIDM), 2011 IEEE Symposium on, pages 341-348. IEEE.

[68] M. Gevrey, I. Dimopoulos, S. Lek (2003). Review and comparison of methods to study the contribution of variables in artificial neural network models. Ecological Modelling, 160(3):249-264.

[69] J. D. Olden, D. A. Jackson (2002). Illuminating the black box: a randomization approach for understanding variable contributions in artificial neural networks. Ecological modelling, 154(1):135-150.

[70] S. Arlot, A. Celisse, et al. (2010). A survey of cross-validation procedures for model selection. Statistics surveys, 4:40-79.

[71] D. R. Legates, G. J. McCabe (1999). Evaluating the use of goodness-offit measures in gic and hydroclimatic model validation. Water resources research, 35(1):233-241. 